\title{
An integrated fuzzy sustainable supplier evaluation and selection framework for green supply chains in reverse logistics
}

\author{
Madjid Tavana ${ }^{1,2}$ (D) $\cdot$ Akram Shaabani $^{3} \cdot$ Francisco J. Santos-Arteaga $^{4} \cdot$ Naser Valaei $^{5}$ \\ Received: 20 February 2021 / Accepted: 3 May 2021 / Published online: 27 May 2021 \\ (C) The Author(s), under exclusive licence to Springer-Verlag GmbH Germany, part of Springer Nature 2021
}

\begin{abstract}
Green supply chain management considers the environmental effects of all activities related to the supply chain, from obtaining raw materials to the final delivery of finished goods. Selecting the right supplier is a critical decision in green supply chain management. We propose a fuzzy green supplier selection model for sustainable supply chains in reverse logistics. We define a novel hierarchical fuzzy best-worst method (HFBWM) to determine the importance weights of the green criteria and sub-criteria selected. The fuzzy extension of Shannon's entropy, a more complex evaluation method, is also used to determine the criteria weights, providing a reference comparison benchmark. Several hybrid models integrating both weighting techniques with fuzzy versions of complex proportional assessment (COPRAS), multi-objective optimization by ratio analysis plus the full multiplicative form (MULTIMOORA), and the technique for order of preference by similarity to ideal solution (TOPSIS) are designed to rank the suppliers based on their ability to recycle in reverse logistics. We aggregate these methods' ranking results through a consensus ranking model and illustrate the capacity of relatively simple methods such as fuzzy COPRAS and fuzzy MOORA to provide robust rankings highly correlated with those delivered by more complex techniques such as fuzzy MULTIMOORA. We also find that the ranking results obtained by these hybrid models are more consistent when HFBWM determines the weights. A case study in the asphalt manufacturing industry is presented to demonstrate the proposed methods' applicability and efficacy.
\end{abstract}

Keywords Green supply chain · Reverse logistics $\cdot$ Hierarchical fuzzy best-worst method $\cdot$ Shannon's entropy $\cdot$ Maximize agreement heuristic $\cdot$ Consensus ranking

\section{Introduction}

Environmental issues related to waste and toxic gas emissions have raised concerns over the environment and public health

Responsible Editor: Philipp Gariguess

Madjid Tavana

tavana@lasalle.edu

1 Business Systems and Analytics Department, Distinguished Chair of Business Analytics, La Salle University, Philadelphia, USA

2 Business Information Systems Department, Faculty of Business Administration and Economics, University of Paderborn, Paderborn, Germany

3 Department of Industrial Management, Faculty of Management and Accounting, Allameh Tabataba'i University, Tehran, Iran

4 Faculty of Economics and Management, Free University of Bolzano, Bolzano, Italy

5 Liverpool Business School, Liverpool John Moores University, Liverpool, UK
(Khor and Udin 2013). Globalization and legal environmental provisions have forced companies and organizations to promote environmental performance (Abdel-Basset et al. 2019). One of the critical matters in this area is recycling, which begs attention. The pressures posed by regulators and stakeholders for recycling benefit the environment and lead to a sustainable competitive advantage (Bai et al. 2019). The principal goal of recycling is to reduce the waste and efficient use of resources, which has both economic and environmental benefits. Due to severe environmental impacts, manufacturers have been encouraged to change their reverse logistics (RL) networks into green concepts and reduce harmful ecological impacts (Haji et al. 2015).

RL refers to operations collecting used goods for reuse, repair, remanufacturing, recycling, or disposal to produce new products (Alkahtani et al. 2021; Chen et al. 2021). Also, $\mathrm{RL}$ is a process of moving a typical product in an inverse path from the mainstream logistics to retrieve value or ensure proper disposal (Hansen et al. 2018; Tavana et al. 2016a, b). Furthermore, it is a tool to recover and recycle or green disposal of goods to reduce pollution (Zarbakhshnia et al. 2019). 
RL helps companies gain a competitive advantage by creating economic value through reuse and retrieval. Being the main step in green supply chain initiatives, RL allows manufacturers to enter the reused products into the production cycle (Mavi et al. 2017). In RL, materials used can be transformed into new products that could return to the same market or other markets (Ribeiro et al. 2021). The core objectives of RL are cost minimization, profit maximization, and environmental benefits (Liao 2018). Companies pursue three main activities in RL: (i) gathering, where consumers discard their used products; (ii) reconstruction, where separation, rehabilitation, or recycling is done; and (iii) demand centers, where restored products are sold (Ravi 2014).

Many manufacturing companies with limited capabilities outsource some of their reconstruction activities to their suppliers. Suppliers rebuild, repair, and recycle the collected products and reconstruct the final products that can be reused in the manufacturing process within RL companies. As environmental agencies and organizations control the industry activities, suppliers play a critical role in the RL companies. Hence, evaluating suppliers and assessing their impacts on the company's productivity are of great importance for RL companies.

In the tire industry, companies operate RL processes to recycle worn-out tires as raw material. In tire and rubber recycling, the process takes place on worn or ruptured tires, which are not repairable and not suitable for use. There are crucial concerns about this process as worn-out tires are among the leading causes of environmental contamination. The spoiled tires are considered hazardous wastes since burning them emanate black and harmful smoke causing air pollution. Burying tires is also detrimental to the environment as they produce dangerous gas bubbles (also known as cavitation), which contaminates underground water resources. Tires can be recycled for different types of products; for instance, they can be used in the hot asphalt production process, where they improve the asphalt durability and increase the asphalt compressive strength. Moreover, recycled tires can also be used in Portland cement, production of new tires, sports fields, shoe industry, flooring, and artificial grass. This study aims to shed light on the waste recycling processes and the environmental pollution concerns in the asphalt manufacturing companies. In this regard, the main empirical contribution of this research focuses on the recycling process of worn-out tires and their use as raw material.

The model proposed to evaluate and rank the set of potential green suppliers incorporates two main novel features. First, it extends the fuzzy best-worst method (BWM) into a hierarchical structure, defining a relatively simple weighting technique whose performance is more consistent than that of more complex methods such as the fuzzy version of Shannon's entropy. Second, we design a hybrid ranking model that incorporates the previous weights into the fuzzy extensions of evaluation techniques such as the complex proportional assessment of alternatives (COPRAS), multiobjective optimization on the basis of ratio analysis (MOORA), MOORA plus full multiplicative form (MULTIMOORA), and the technique for order of preference by similarity to ideal solution (TOPSIS). The empirical results obtained allow for a direct comparison of the rankings provided by these techniques and their aggregation into a unique consensus ranking via the maximize agreement heuristic (MAH) method.

The main contributions of this research can be summarized as follows:

- Our study case focuses on tire recycling and the use of recycled tires as raw materials, an important problem that has received relatively little attention in the literature. Tires are made of polymeric materials that do not decompose easily in nature, constituting a severe long-term problem that cannot be initially solved by burning or burying them. Two main sets of consequences follow from their correct re-utilization. From an environmental viewpoint, worn-out recycling tires reduce waste and reinforces the material cycle in nature. From a financial viewpoint, recycled tires can be incorporated into production cycles, becoming a source of economic profitability and helping industrial development; a particularly important feature is less developed countries.

- We develop a novel hierarchical extension of the fuzzy best-worst method, denoted by HFBWM, which allows for the simultaneous determination of the weights of criteria and sub-criteria within a fuzzy environment.

- We propose several enhanced hybrid ranking models that incorporate HFBWM and fuzzy Shannon's entropy, allowing for direct comparisons across methods and resulting in more accurate aggregate results.

The rest of this research is arranged in the following order: In the second section, this study reviews the current literature on RL, tire recycling, and evaluation and assortment of green suppliers. The literature review generates the supplier evaluation criteria for tire recycling in RL. In the third section, this research presents the suggested fuzzy green supplier selection model. In the fourth section, a case study in the asphalt manufacturing industry is presented to stress the proposed method's applicability and efficacy. In the final section, we conclude with a discussion and conclusions.

\section{Literature review}

In this part, the present study provides a concise review of the literature on RL, tire recycling, and green supplier evaluation and selection. 


\section{Reverse logistics}

Today, RL has attracted many manufacturers (Ramírez and Morales 2014), and the RL operations refer to all restructuring actions in which the factory directly or indirectly benefits from the changes. RL is related to the process of retrieval of goods at the final stage of the lifecycle for regeneration, recycling, or green disposal (Zarbakhshnia et al. 2019). RL is the efficient control of raw materials, finished goods, and in-process inventory from production to consumption to regain value from the disposed goods (Rogers and Tibben-Lembke 1999). Figure 1 presents an RL system. A typical RL system involves product acquisition, collection, examination and classification, disposal, and redistribution processes. The disposition process includes five steps of repair, refurbish, remanufacture, cannibalize, and recycle. In this research, the focus is on the recycling step of the disposition process. Next, this study presents the RL processes from a literature perspective (Agrawal et al. 2016a, b; Rachih et al. 2019).

Reverse logistic processes encompass different stages that include product acquisition (gatekeeping), collection (gathering), inspection and sorting, disposition, and redistribution, all of which are described below.

\section{Product acquisition (gatekeeping)}

Product acquisition refers to operations in which goods are collected and returned from the end-users (Jayaraman et al. 2008). In this process, companies use agents in the purchasing sector to identify the market for consumer goods and buy the used or returned products (Agrawal et al. 2016b).

\section{Collection (gathering)}

Collection or gathering refers to goods received from the interior and exterior end-users and includes the processes of delivery of the returned goods and their transport (Lambert et al. 2011). In this process, the company takes ownership of the products by purchasing them from retailers (Agrawal et al. 2016a). After the purchase, products are harvested and prepared for recycling, repair, or disposal (Agrawal et al. 2016b). Three methods of the collection include direct contact with customers, retailers, or a third party.

\section{Inspection and sorting}

The collected products often have different qualities and appearances. Therefore, inspection and isolation are needed to sort these products. In this step, a separate inspection is carried out to categorize these products accordingly (Agrawal et al. 2016b). Generally, sorting involves deciding on the goods and products returned (Lambert et al. 2011). This process can be complex when hazardous goods are being sorted.

\section{Disposition}

Disposition refers to goods that are either defective or have reached the end of their lifetime so that they can be reproduced and enter the consumption cycle. Returned products can also be used as raw material in the production of new products (Jayaraman et al. 2008). Generally, this process involves deciding whether to repair, refurbish, remanufacture, cannibalize, or recycle the product.

\section{Redistribution}

Redistribution is the process of diverting reusable goods to a market for resale purposes. Reusable goods can be traded through redistribution on a secondary market (Agrawal et al. 2016a).

Fig. 1 The process flow in RL

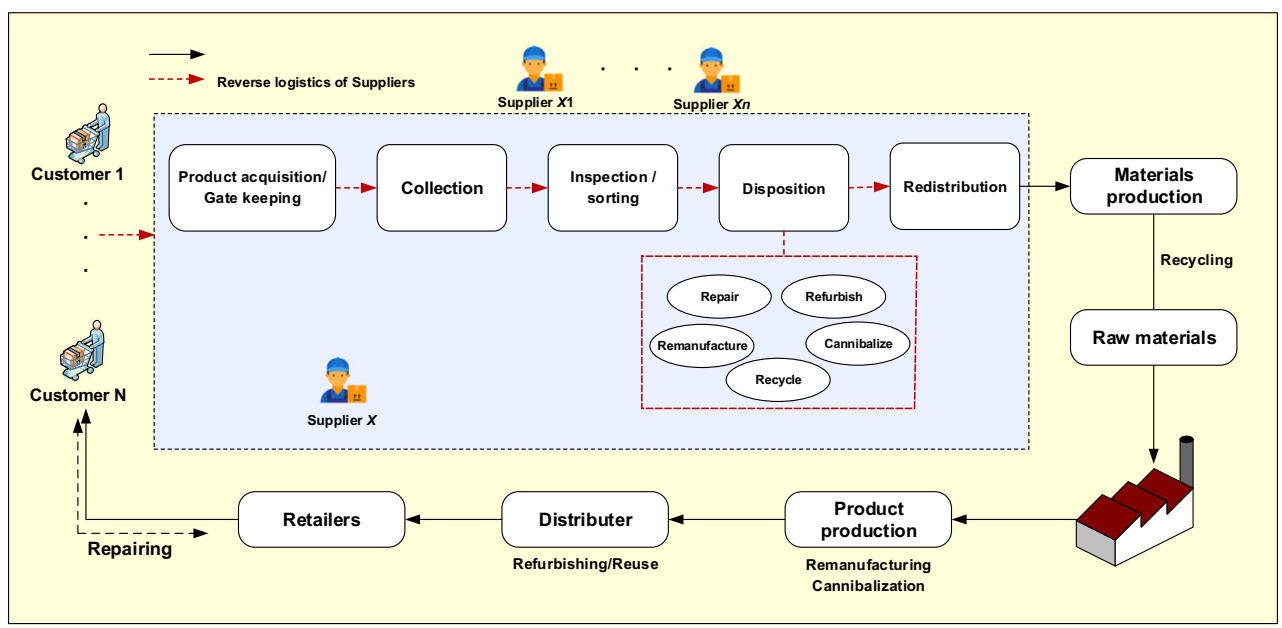




\section{Tire recycling}

The primary consumers of tire products are asphalt manufacturing and automotive industries. Tire waste is usually obtained from the tire production process or products consumed by customers (Fukumori et al. 2002). Tire waste recycling is an example of recycled solids that has received considerable attention due to its environmental benefits (Price and Smith 2015). The natural destruction of tires is often timeconsuming, expensive, and causes environmental pollution. The environmentally conscious approach to tackle this problem is recycling and reusing the tire waste (Adhikari 2000). These tire recycling approaches lead to economic and social benefits such as reducing energy consumption, diminishing production cost by combining rubber powder from recycled rubber, and reducing rubber waste (Fang et al. 2001).

Tire recycling methods are divided into mechanical and chemical approaches. In the mechanical approach, tires are divided into smaller pieces. This process is done in several steps by shredder and granulator machines. Each step produces different products, which are used in various industries. Some industries use coarse granules, and others use a very soft tire powder. In the chemical approach, the tire is burned, and the metal wires or the tire become pyrolyzed. In pyrolysis, the tire is burned in a vacuum, and several products are extracted, such as diesel fuel and oil. Recycled tire products vary based on the mechanical or chemical recycling: rubber granulate, rubber powder, recycled metal, reclaimed tire, asphalt and bitumen polymer, gasoline fuel, and the car battery.

\section{Green supplier assessment and assortment}

Supplier assessment and assortment have a significant role in creating an impressive and competitive chain (Freeman and Chen 2015; Ghadimi et al. 2019). Due to outsourcing activities, companies' dependence on suppliers has increased; thus, supplier evaluation and selection have become of great importance. The supplier evaluation and selection procedure are done with different objectives (Govindan et al. 2015b). In addition, as public awareness about the environmental impacts increases, principles and strategies for green supply chain activities happen to be the key success factors for companies (Liao et al. 2016). One of the critical principles in green activities is removing or reducing wastes, which causes hazardous solid waste, energy losses, and greenhouse gas emissions. Improving waste management can turn into a core competency for suppliers (Torabzadeh Khorasani 2017). This research conducted a thorough literature review to explore the environmental dimensions and the primary standards for assessing and selecting the best suppliers for tire recycling presented in Table 1.

Different approaches have been suggested and applied for green supplier assessment and assortment, including grey-based
Decision-Making Trial and Evaluation Laboratory (DEMATEL) (Fu et al. 2012), grey analytic network process (ANP) (Dou et al. 2014), data envelopment analysis (DEA) (Dobos and Vörösmarty 2014), fuzzy additive ratio assessment and multisegment goal programming (Liao et al. 2016), the qualitative flexible multiple method (Wang et al. 2017), DEMATEL-ANP (Jiang et al. 2018), TOPSIS (Shafique 2018), elimination and choice expressing reality (Gitinavard et al. 2018), Visekriterijumska Optimizcija I Kaompromisno Resenje (VIKOR) (Demir et al. 2018), TOPSIS-VIKOR-grey relational analysis (Banaeian et al. 2018), the preference ranking organization technique for improving assessments (Abdullah et al. 2018), fuzzy analytic hierarchy process (AHP) (Zafar et al. 2019), BWM and TOmada de Decisao Interativa Multicriterio (TODIM) (Bai et al. 2019), and hybrid FUll COnsistency Method (FUCOM) and rough simple additive weighting (SAW) techniques (Durmić et al. 2020).

Prakash and Barua (2015) studied RL obstacles and used AHP and TOPSIS to rank barriers. Similarly, Bouzon et al. (2016) investigated RL obstacles in Brazil's electronic industry, identified barriers based on expert opinion using the fuzzy Delphi method, and ranked them by applying the AHP approach. Govindan et al. (2016) used a model of multiobjective particle swarm optimization for an effective and viable RL network outline considering the environmental, social, and economic domains. Moreover, Mangla et al. (2016) used DEMATEL and AHP approaches to examine the RL critical success elements in Indian industries. Ravi and Shankar (2017) investigated RL principles in the automobile industry using interpretive structural modeling.

\section{COPRAS, MULTIMOORA, and TOPSIS}

MCDM models are applied to identify and select the best possible solution from a set of alternatives based on different decision criteria. For example, prior research has used COPRAS to plan water transfer between basins (Roozbahani et al. 2020), rank hybrid wind farms (Dhiman and Deb 2020), select green suppliers (Kumari and Mishra 2020), evaluate the performance of contractors (Jasim 2021), assess construction project safety (Wei et al. 2021), rank effective risks in natural gas supply projects (Balali et al. 2021), and evaluate COVID19 regional safety (Hezer et al. 2021). In addition, previous studies have used MULTIMOORA for selecting suppliers (Tavana et al. 2020a, b) and logistic service providers (Sarabi and Darestani 2021), examining the barriers to the adoption of renewable energy (Asante et al. 2020), selecting car subscription station sites (Lin et al. 2020a, b), choosing stable battery suppliers (Wang et al. 2021a, b), and evaluating technology project review experts (Wang et al. 2021c, d). A similar range of applications arises when considering previous research works that implement TOPSIS, including supplier selection (Lei et al. 2020), the evaluation of unusual 
Table 1 Environmental dimensions and criteria for green supplier selection

\begin{tabular}{|c|c|c|c|c|}
\hline \multirow{2}{*}{$\begin{array}{l}\text { Environmental dimensions } \\
\text { Pollution controls } \\
\text { C1 }\end{array}$} & \multicolumn{2}{|c|}{ Environmental criteria } & \multirow{2}{*}{$\begin{array}{l}\text { Objective } \\
\text { MIN }\end{array}$} & \multirow{2}{*}{$\begin{array}{l}\text { References } \\
\text { Cao et al. 2015; Kannan et al. 2015; Datta et al. } \\
\text { 2012; Lee et al. 2009; Noci 1997; Fallahpour } \\
\text { et al. 2016; Qin et al. 2017; Shaik and } \\
\text { Abdul-Kader 2011; Yeh \& Chuang, } 2011\end{array}$} \\
\hline & $\mathrm{C} 11$ & Energy consumption & & \\
\hline & $\mathrm{C} 12$ & Use of harmful material & MIN & $\begin{array}{l}\text { Kannan et al. 2015; Datta et al. 2012; Lee et al. } \\
\text { 2009; Govindan et al. 2015a }\end{array}$ \\
\hline & $\mathrm{C} 13$ & Pollution control initiatives & MAX & Kannan et al. 2015 \\
\hline & $\mathrm{C} 14$ & Pollution decrease capability & MAX & $\begin{array}{l}\text { Kannan et al. 2015; Humphreys et al. 2006; } \\
\text { P. Humphreys et al. } 2003\end{array}$ \\
\hline \multirow[t]{3}{*}{$\begin{array}{l}\text { Green product } \\
\mathrm{C} 2\end{array}$} & $\mathrm{C} 21$ & Recycle & MAX & $\begin{array}{l}\text { Kannan et al. 2015; Datta et al. 2012; Lee et al. } \\
\text { 2009; Büyüközkan and Çifçi 2012; Govindan } \\
\text { and Sivakumar 2016; Jabbour and Jabbour } \\
\text { 2009; Shaik and Abdul-Kader 2011; } \\
\text { P. Humphreys et al. 2006; P. K. Humphreys } \\
\text { et al. } 2003\end{array}$ \\
\hline & $\mathrm{C} 22$ & Reuse & MAX & $\begin{array}{l}\text { Jabbour and Jabbour 2009; Shaik and } \\
\text { Abdul-Kader 2011; P. Humphreys et al. } 2006\end{array}$ \\
\hline & $\mathrm{C} 23$ & Remanufacture & MAX & $\begin{array}{l}\text { Hashemi et al. 2015; Kannan et al. 2015; } \\
\text { Jabbour and Jabbour 2009; Datta et al. 2012; } \\
\text { Shaik and Abdul-Kader 2011; P. Humphreys } \\
\text { et al. 2006; P. K. Humphreys et al. } 2003\end{array}$ \\
\hline \multirow{2}{*}{$\begin{array}{l}\text { Environment } \\
\text { protection/environment } \\
\text { management }\end{array}$} & $\mathrm{C} 31$ & The capability of preventing pollution & MAX & Kannan et al. 2015 \\
\hline & $\mathrm{C} 32$ & Continuous pursuit and regulatory compliance & & Kannan et al. 2015 \\
\hline \multirow[t]{2}{*}{$\mathrm{C} 3$} & $\mathrm{C} 33$ & Environmental management system & MAX & $\begin{array}{l}\text { Kannan et al. 2015; Çifçi and Büyüközkan 2011; } \\
\text { Rezaei et al. 2016; Yazdani } 2017\end{array}$ \\
\hline & $\mathrm{C} 34$ & Environmental protection plans & MAX & Kannan et al. 2015 \\
\hline \multirow{3}{*}{$\begin{array}{l}\text { Pollution production } \\
\text { C4 }\end{array}$} & $\mathrm{C} 41$ & Production of polluting agents & MIN & Bai and Sarkis 2010 \\
\hline & $\mathrm{C} 42$ & Production of toxic products & MIN & Bai and Sarkis 2010 \\
\hline & $\mathrm{C} 43$ & Waste production & MIN & Bai and Sarkis 2010 \\
\hline
\end{tabular}

emergency events (Zhan et al. 2020), the assessment of lake eutrophication levels (Lin et al. 2020a, b), sustainable supply chain risk management (Abdel-Basset and Mohamed 2020), risk analysis of cutting system (Kushwaha et al. 2020), transportation management (Sarkar and Biswas 2021), risk prioritization in self-driving vehicles (Bakioglu and Atahan 2021), and the evaluation of renewable energy production capabilities (Wang et al. 2021a, b, c, d).

\section{BWM and fuzzy Shannon's entropy}

BWM, proposed by Rezaei (2016), is an MCDM technique used to determine the weights of criteria. BWM has been developed and applied by researchers across several disciplines. For instance, Bonyani and Alimohammadlou (2019) integrated BWM with ANP to improve pair-wise comparison processes. Amiri et al. (2020) developed a group BWM and integrated it with a fuzzy preference programming method to examine hospital performance. Other studies have also used BWM for evaluation purposes, including the performance of solid waste management (Behzad et al. 2020), insurance companies (Dwivedi et al. 2021), and healthcare departments (Torkayesh et al. 2021), driver's behavior in road safety (Moslem et al. 2020), the green performance of airports (Kumar et al. 2020), selection of providers (Muravev and Mijic 2020), and ship recycling (Soner et al. 2021). Similarly, the method based on Shannon's entropy is an appropriate technique for specifying the relevance of weights in multiple attribute decision-making methods. For instance, this method has been used to rank cities (Storto 2016), assess flood vulnerability (Yang et al. 2018a, b), analyze barriers to the implementation of continuous improvement (Tavana et al. 2020a, b), study surface air temperature and rainfall (Ray and Chattopadhyay 2021), and rank the structural analysis of software applications (Jarrah et al. 2021).

\section{Methodology}

This study uses a fuzzy green supplier selection model for sustainable supply chains in RL. To prioritize those green 
suppliers with a robust ability to recycle in RLs, we use fuzzy extensions of COPRAS, MULTIMOORA, and TOPSIS. COPRAS, MULTIMOORA, and TOPSIS are robust MCDM techniques applied to evaluate the performance of a series of alternatives according to different criteria. The relative importance assigned to these criteria is determined by the separate implementation of the fuzzy extension of Shannon's entropy and our proposed approach, namely, HFBWM. This

Fig. 2 Proposed framework

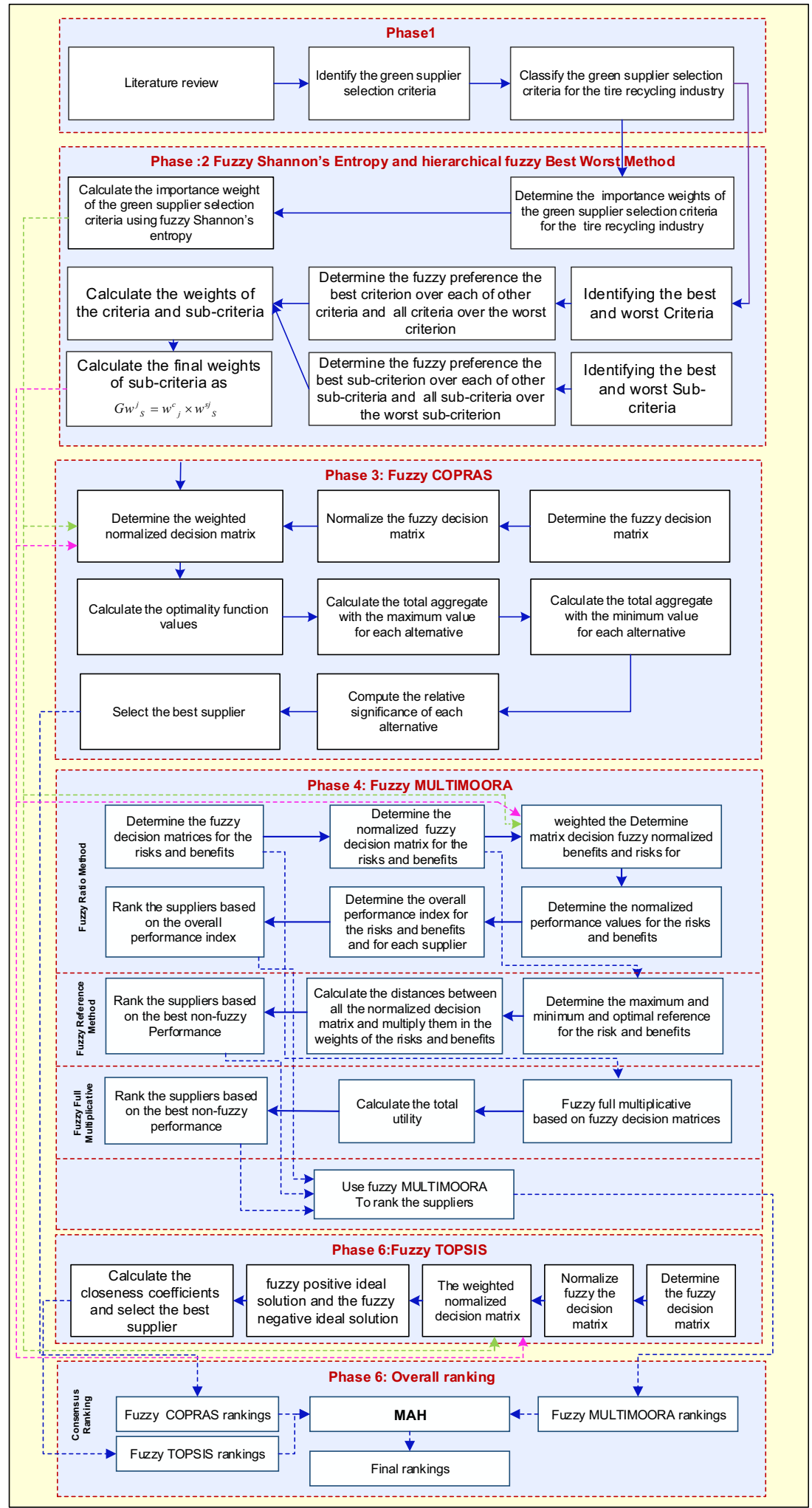


Fig. 3 The green supplier selection criteria

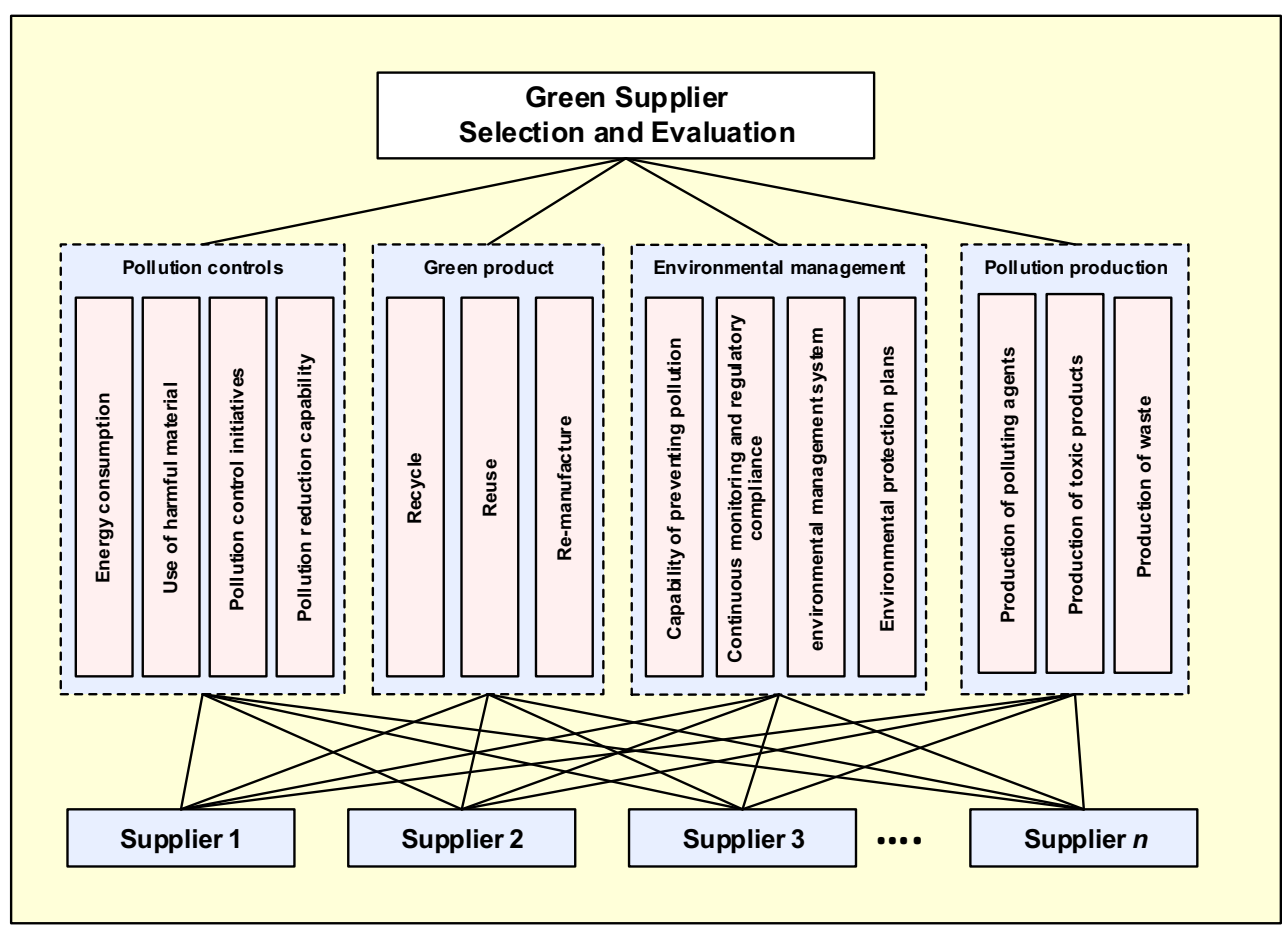

latter method constitutes one of the main contributions of the current study. We extend FBWM into HFBWM to evaluate the weights of the criteria and sub-criteria used to rank alternatives through COPRAS, MULTIMOORA, and TOPSIS. Integrating these MCDM methods into hybrid evaluation techniques aims to improve the accuracy and robustness of the results compared to those obtained when applying a single method. We also use fuzzy Shannon's entropy to determine the weights of the criteria and sub-criteria of the different hybrid models, allowing us to compare the rankings derived from both weighting techniques. The comparisons performed both across hybrid MCDM models and between weighting techniques aim at improving the quality of decision-making and the reliability of the results obtained.

As depicted in Fig. 2, the procedure of the current research entails six phases. First, this research reviews the literature and identifies the green supplier assortment benchmarks. In addition, the green supplier assortment benchmarks for the tire recycling industry are classified accordingly. Second, this research uses fuzzy Shannon's entropy and HFBWM to compute the importance weight of the green supplier assessment benchmarks. Third, this study uses fuzzy COPRAS in phase 3 , fuzzy MULTIMOORA in phase 4, and fuzzy TOPSIS in phase 5 to rank the suppliers. We compare the rankings provided by the set of methods implemented throughout the evaluation procedure, illustrating fuzzy COPRAS and fuzzy MOORA's capacity to deliver sufficiently robust rankings relative to more complex techniques such as fuzzy MULTIMOORA. Finally, in phase 6, this research aggregates the rankings obtained from the fuzzy COPRAS, fuzzy
MULTIMOORA, and fuzzy TOPSIS techniques using the maximize agreement heuristic (MAH) method proposed by Beck and Lin (1983) to reach an agreement for the rankings produced by the different hybrid methods. Several consensus ranking methods, such as the Copeland approach, exist. MAH is commonly used since it provides an effective consensus ranking framework that maximizes agreement in decisionmaking. It is a practical method that has been introduced to motivate the application of our integrated model by future researchers. We conclude by highlighting the hybrid models' capacity based on HFBWM to provide consistent ranking results while requiring a simpler evaluation framework than those based on the fuzzy extension of Shannon's entropy.

In phase 1, this study conducted a rigorous literature review and explored the benchmarks and environmental dimensions to assess and assort the best suppliers for tire recycling. As depicted in Fig. 3, the green supplier selection benchmarks chosen in this study were classified into the four environmental dimensions of pollution control, green product, environment management, and pollution production.

\section{Fuzzy Shannon's entropy method}

Entropy refers to the quantitative measure of information (Shannon 1948), leading to a higher degree of compression (Naidu et al. 2018). According to Pourhamidi (2013), the entropy approach has its roots in the Boltzmann entropy of conventional statistical methods. Fuzzy entropy refers to the fuzzy information obtained from the fuzzy system (Al-Sharhan et al. 2001), and it differs from Shannon entropy, which is an 
estimate of unpredictability. The difference is mainly the probabilistic nature of Shannon entropy. According to Lotfi and Fallahnejad (2010), it is a good technique in specifying the relevant weights in multiple attribute decision-making methods. Previous research improved this method for fuzzy data (Lotfi and Fallahnejad 2010). The steps of the fuzzy Shannon's entropy approach are presented as follows:

Step 1: This step involves transforming the fuzzy numbers to set-level data. In a fuzzy variable $\tilde{x_{i j}}$, the $\alpha$-level set indicates a class of intervals that has a participation of minimum value $\alpha$, i.e., $\left(\widetilde{x_{i j}}\right)_{\alpha}=$ $\left\{X_{i j} \in R \operatorname{Rlw}_{x_{i j}}\left(X_{i j}\right) \geq \alpha\right\}$. The following formula indicates the $\alpha$-level set:

$$
\begin{aligned}
& {\left[\left(\widetilde{x_{i j}}\right)_{\alpha}^{l},\left(\widetilde{x_{i j}}\right)_{\alpha}^{u}\right]} \\
& =\left[\operatorname{Min}_{x_{x j}}\left\{x_{i j} \in R \mid u_{x_{i j}}\left(X_{i j}\right) \geq \alpha\right\}, \operatorname{Max}_{x_{i j}}\left\{x_{i j} \in R \mid u_{x_{i j}}\left(X_{i j}\right) \geq \alpha\right\}\right]
\end{aligned}
$$

in which $0<\alpha \leq 1$.

Through the different levels of confidence interval limits in terms of $1-\alpha$, the fuzzy data is transformed to the different interval set values of $\left\{\left(\widetilde{x}_{i j}\right)_{\alpha} \mid 0<\alpha \leq 1\right\}$.

Step 2: In this step, the $p_{i j}^{l}$ and $p_{i j}^{u}$ values are calculated through the parameters of Eq. (1):

$$
\begin{aligned}
p_{i j}^{l} & =\frac{x_{i j}^{l}}{\sum_{j=1}^{m} x_{i j}^{u}}, p_{i j}^{u}=\frac{x_{i j}^{u}}{\sum_{j=1}^{m} x_{i j}^{u}}, j=1, \ldots, m ; i \\
& =1, \ldots, n
\end{aligned}
$$

Step 3: In the following stage, the $h_{i}^{l}$ and $h_{i}^{u}$ formulas as min and max interval values are computed through Eq. (2):

$$
\begin{array}{ll}
h_{i}^{l}=\operatorname{Min}\left\{-h_{0} \sum_{j=1}^{m} p_{i j}^{l} \cdot \ln p_{i j}^{l},-h_{0} \sum_{j=1}^{m} p_{i j}^{u} \cdot \ln p_{i j}^{u}\right\}, & i=1, \ldots, n \\
h_{i}^{u}=\operatorname{Max}\left\{-h_{0} \sum_{j=1}^{m} p_{i j}^{l} \cdot \ln p_{i j}^{l},-h_{0} \sum_{j=1}^{m} p_{i j}^{u} \cdot \ln p_{i j}^{u}\right\}, & i=1, \ldots, n
\end{array}
$$

in which $h_{0}=(\ln m)^{-1}$ and $p_{i j}^{l} \cdot \ln p_{i j}^{l}$ or $p_{i j}^{u} \cdot \ln p_{i j}^{u}$ are zero in case $p_{i j}^{l}=0$ or $p_{i j}^{u}=0$.

Step 4: In this step, the $d_{i}^{l}$ and $d_{i}^{u}$ diversification interval values are assigned in Eq. (3):

$d_{i}^{l}=1-h_{i}^{u}, d_{i}^{u}=1-h_{i}^{l}, i=1, \ldots, n$

Step 5: In this step, the $w_{i}^{l}$ and $w_{i}^{u}$ values are assigned as the base and upward value limits of the interim weights of the attribute $i$, where $i=1, \ldots, n$, as shown in Eq. (4):

$$
w_{i}^{l}=\frac{d_{i}^{l}}{\sum_{s=1}^{n} d_{s}^{u}}, w_{i}^{u}=\frac{d_{i}^{u}}{\sum_{s=1}^{n} d_{s}^{l}}
$$

Step 6: This research calculates $w_{i}^{\prime}=\frac{w_{i}^{l}+w_{i}^{u}}{2}$, then computes $\sum_{i}^{n} w_{i}^{\prime}$, and finally calculates $w_{i}$ using Eq. (5) to obtain the final weight:

$$
w_{i}=\frac{w_{i}^{\prime}}{\sum_{i}^{n} w_{i}^{\prime}}
$$

\section{Hierarchical fuzzy best-worst method}

Rezaei (2015) proposed the best-worst method as an MCDM technique used to determine the weights of criteria via pairwise comparisons of the best criterion relative to all the other criteria and all the criteria relative to the worst criterion (Bonyani and Alimohammadlou 2019). Immediate extensions were developed by Tabatabaei et al. (2019), who introduced the Hierarchical BWM, and Guo and Zhao (2017), who proposed a fuzzy version of the BWM. The HBWM allows considering the weights of the criteria and sub-criteria within a simultaneous programming model so as to calculate the global weights of the set of sub-criteria (Ren and Toniolo 2021).

We propose the Hierarchical Fuzzy Best-Worst Method (HFBWM) based on the fuzzy BWM (FBWM) introduced by Guo and Zhao (2017) and the HBWM defined by Tabatabaei et al. (2019). The steps of the HFBWM can be summarized as follows:

Step 1: Identify the set of criteria $\left\{C_{1}, C_{2}, \ldots, C_{n}\right\}$ and subcriteria $\left\{C_{1 S}, C_{2 S}, \ldots, C_{n S}\right\}$.

Step 2: Identify the best (most important) criteria and subcriteria, $\mathbf{B}$, and the worst (least important) criteria and sub-criteria, $\mathbf{W}$.

Step 3: Determine the fuzzy preference for the best criterion over each of the other criteria on a scale from 1 to 5 . The fuzzy best-to-others criteria are defined as follows:

$\widetilde{A}_{B}=\left(\widetilde{a}_{B 1}, \widetilde{a}_{B 2}, \ldots, \widetilde{a}_{B n}\right)$

where $\widetilde{a}_{B j}$ is the fuzzy preference of $\mathbf{B}$ over $C_{j}(j=1$, $2, \ldots, n)$ and $\widetilde{a}_{B B}=(1,1,1)$.

Step 4: Determine the fuzzy preference of all the criteria over the worst criterion on a scale from 1 to 5 . The fuzzy others-to-worst criteria are defined as follows:

$\widetilde{A}_{W}=\left(\widetilde{a}_{1 W}, \widetilde{a}_{2 W}, \ldots, \widetilde{a}_{n W}\right)$

where $\tilde{a}_{j W}$ is the fuzzy preference of $C_{j}(j=1,2, \ldots$, $n)$ over $\mathbf{W}$ and $\tilde{a}_{W W}=(1,1,1)$. 
Step 5: Determine the fuzzy preference of the best subcriterion over each of the other sub-criteria in a scale from 1 to 5 . The fuzzy best-to-others sub-criteria are defined as follows:

$\widetilde{A}_{B S}=\left(\widetilde{a}_{B 1}, \widetilde{a}_{B 2}^{j}, \ldots, \widetilde{a}_{B n}\right)$

where $\widetilde{a}_{B S}$ is the fuzzy preference of the best subcriterion over the S-th sub-criterion within the $\mathrm{j}$-th criterion and $\widetilde{a}_{B B}^{j}=(1,1,1)$.

Step 6: Determine the fuzzy preference of all sub-criteria over the worst sub-criterion on a scale from 1 to 5 . The fuzzy others-to-worst sub-criteria are defined as follows:

$\widetilde{A}_{S W}=\left(\widetilde{a}^{j}{ }_{1 W}, \widetilde{a}^{j}{ }_{2 W}, \ldots, \widetilde{a}_{n W}^{j}\right)$

where $\widetilde{a}_{S W}^{j}$ is the fuzzy preference of the S-th subcriterion over the worst sub-criterion within the $\mathrm{j}$-th criterion and $\widetilde{a}_{W W}^{j}=(1,1,1)$.

Step 7: Calculate the weights of the criteria $\left(w^{c}{ }_{1}, w_{2}^{c}, \ldots\right.$, $\left.w_{n}^{c}\right)$ and sub-criteria $\left(w_{1}^{j}, w_{2}^{j}, \ldots, w_{S}{ }^{j}\right)$, and then calculate the final weights of the sub-criteria as $G w^{j}{ }_{S}=$ $w_{j}^{c} \times w^{s j}$ :

$$
\begin{aligned}
& \min \widetilde{\xi}+\sum_{j} \widetilde{\xi}_{j S . t} \\
& :\left|w^{w_{B}} / w_{j}-\widetilde{a}_{B j}\right| \leq \widetilde{\xi}, \quad \forall j=1, \ldots,\left.n\right|^{w_{j}} / w_{W}-\widetilde{a}_{j W} \mid \\
& \leq \widetilde{\xi}, \forall j=1, \ldots, S\left|w_{B}^{j} / w_{w_{S}^{j}}-a_{B S}^{r}\right| \leq \widetilde{\xi}_{j}, \\
& \forall j=1, \ldots,\left.S||^{j}\right|_{w_{W}^{j}} \underset{\sim_{S W}^{j}}{-\vec{a}_{S W}} \mid \leq \widetilde{\xi}_{j}, \forall j=1, \ldots, \\
& n G w_{S}^{j}=w_{j} \times w_{S}^{j} \sum_{j=1}^{n} R\left(w_{j}\right)=1, \sum_{j=1}^{n} R\left(w_{S}^{j}\right) \\
& =1, l_{j}^{w} \leq m_{j}^{w} \leq u_{j}^{w}, \quad \forall j=1, \ldots, n l_{j}^{w}, m_{j}^{w}, u_{j}^{w} \geq 0, \forall j \\
& =1, \ldots, n \\
& \min \widetilde{\xi}+\sum_{j} \widetilde{\xi}_{j s . t}:\left|w_{B}-\widetilde{\mathrm{a}}_{B j} w_{j}\right| \leq \widetilde{\xi}, \quad \forall j \\
& =1, \ldots, n\left|w_{j}-\tilde{a}_{j w} w_{W}\right| \leq \widetilde{\xi}, \quad \forall j \\
& =1, \ldots, S\left|w_{B}^{j}-a_{B S}^{j} w_{S}^{\widetilde{\tau}}\right| \leq \widetilde{\xi} ; \quad \forall j \\
& =1, \ldots, S\left|w_{S}^{j}-\widetilde{a}_{S W}^{j} w_{W}^{j}\right| \leq \widetilde{\xi}_{j}, \quad \forall j \\
& =1, \ldots, n G w_{S}^{j}=w_{j} \times w_{S}^{j} \sum_{j=1}^{n} R\left(w_{j}\right) \\
& =1, \sum_{j=1}^{n} R\left(w_{S}^{j}\right)=1, l_{j}^{w} \leq m_{j}^{w} \leq u_{j}^{w}, \forall j \\
& =1, \ldots, n l_{j}^{w}, m_{j}^{w}, u_{j}^{w} \geq 0, \quad \forall j=1, \ldots, n(10-2) \\
& R\left(w_{j}\right), R\left(w_{S}^{j}\right)=\frac{l_{j}^{w}+4 m_{j}^{w}+u_{j}^{w}}{6}
\end{aligned}
$$

In Model (10-2), $R\left(w_{j}\right)$ and $R\left(w_{S}^{j}\right)$ are the average weights of the criteria and sub-criteria, $w_{j}$ and $w_{S}^{j}$, respectively:

The consistency ratio of the comparisons is calculated according to Eq. (12) and Table 2 as follows:

Consistency $\quad$ Ratio $=\frac{\xi^{*}}{\text { Consistency Index }}$

where $\xi^{*}=\widetilde{\xi}+\sum_{j} \widetilde{\xi}_{j}$ for all criteria and sub-criteria.

\section{Fuzzy COPRAS}

COPRAS is a multiple attribute decision-making approach developed by Zavadskas et al. (1994). The COPRAS approach calculates the solution by considering the best solution ratio. This approach surmises the proportionate and direct association between the importance-efficiency measures of checked versions and a system of criteria in which it explains the alternatives, weights, and values of the criteria accordingly (Yazdani et al. 2015). Zavadskas and Antucheviciene (2007) developed the fuzzy COPRAS approach. The phases of the ranking process used for fuzzy COPRAS (Zarbakhshnia et al. 2018) are appended below:

Step 1: According to Table 3, the fuzzy decision matrix (DM) is built in this step:

$$
\widetilde{X}=\left[\begin{array}{cccc}
{\left[x_{11}^{l}, x_{11}^{m}, x_{11}^{u}\right]} & {\left[x_{12}^{l}, x_{12}^{m}, x_{12}^{u}\right]} & \ldots & {\left[x_{1 n}^{l}, x_{1 n}^{m}, x_{1 n}^{u}\right]} \\
\cdot & \cdot & \ldots & \cdot \\
\cdot & \cdot & \cdot & \vdots \\
{\left[x_{m 1}^{l}, x_{m 1}^{m}, x_{m 1}^{u}\right]} & {\left[x_{m 2}^{l}, x_{m 2}^{m}, x_{m 2}^{u}\right]} & \ldots & {\left[x_{m n}^{l}, x_{m n}^{m}, x_{m n}^{u}\right]}
\end{array}\right]
$$

The $m$ parameter in the matrix outlines how many alternatives are assigned, and the $n$ parameter highlights the existing benchmarks, and the xmn parameter indicates the efficiency of alternative $i$ in criteria $j$. Table 3 shows the guidelines used for the conversion process of fuzzy membership functions (M. P. Amiri 2010; Zarbakhshnia et al. 2018).

Step 2: In this stage, the fuzzy normalization DM is calculated for estimating its analogous sufficiency. As $\widetilde{X}_{i j}^{*}=\left(x_{i j}^{*^{*}}, x_{i j}^{m^{*}}, x_{i j}^{u^{*}}\right)$ and $\forall i, j$,

$$
\begin{aligned}
& x_{i j}^{l *}=x_{i j}^{l} / \sqrt{\sum_{i=1}^{m}\left[\left(x_{i j}^{l}\right)^{2}+\left(x_{i j}^{m}\right)^{2}+\left(x_{i j}^{u}\right)^{2}\right]} \\
& x_{i j}^{m *}=x_{i j}^{\mathrm{m}} / \sqrt{\sum_{i=1}^{m}\left[\left(x_{i j}^{l}\right)^{2}+\left(x_{i j}^{m}\right)^{2}+\left(x_{i j}^{u}\right)^{2}\right]}
\end{aligned}
$$


Table 2 Consistency index in BWM

\begin{tabular}{llllll}
\hline$a_{B W}, a_{B W}^{j}$ & Exactly equal (E) & Slightly strong (SS) & Fairly strong (FS) & Very strong (VS) & Absolutely strong (AS) \\
\hline $\mathrm{CI}$ & 3.00 & 3.80 & 5.29 & 6.69 & 8.04 \\
\hline
\end{tabular}

$$
x_{i j}^{u^{*}}=x_{i j}^{u} / \sqrt{\sum_{i=1}^{m}\left[\left(x_{i j}^{l}\right)^{2}+\left(x_{i j}^{m}\right)^{2}+\left(x_{i j}^{u}\right)^{2}\right]}
$$

Step 3: In this stage, the weight of the benchmarks that were calculated utilizing the fuzzy Shannon is computed.

Step 4: In this stage, the weighted normalized DM is calculated.

Step 5: In this stage, higher values of the sum of attributes $\widetilde{p_{j}}$ are preferred for each alternative (optimization direction is maximization), with $k$ representing the number of attributes that must be maximized:

$\tilde{p}_{j}=\sum_{i=1}^{k} \tilde{x}_{i j}$

Step 6: In this stage, lower values of the sum of attributes $\widetilde{R_{j}}$ are preferred for each alternative (optimization direction is minimization), with $(m-k)$ representing the number of attributes that must be minimized:

$\widetilde{R_{j}}=\sum_{i=K+1}^{m} \tilde{x_{i j}}$

Step 7: In this stage, the lower bound of $\widetilde{R_{j}}$ as $\widetilde{R}$ minimum is calculated:

$\widetilde{R_{\min }}=\min _{j} \widetilde{R_{j}} ; j=1,2, \ldots, n$

Step 8: In this stage, the comparative importance of every variable is calculated:

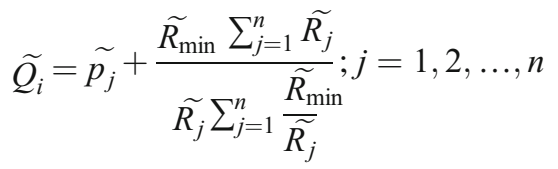

Step 9: In this stage, the function to a non-fuzzy value using Eq. (21) is defuzzified:

$x_{i j}=\frac{\left(x_{i j}^{u}-x_{i j}^{l}\right)+\left(x_{i j}^{m}-x_{i j}^{l}\right)}{3}+x_{i j}^{l}$

Step 10: In this stage, the best alternative is chosen according to Eq. (22) in which the upper weight limit of the alternatives is calculated according to the preference value:

$K=\max _{j} Q_{j} ; j=1,2, \ldots, n$

Step 11: In this stage, the scope of parameters in every variable is computed with Eq. (23). Furthermore, all numbers are defuzzified in this phase:

$K_{j}=\frac{Q_{j}}{Q_{\max }} \times 100 \% ; j=1,2, \ldots, n$

In this equation, $Q_{j}$ and $Q_{\max }$ are referred to as the nonfuzzified comparative importance of each alternative as well as the best alternative value. With regard to the $K_{j}$ parameter, the alternative values are classified and graded downward so that the superior value of $K_{j}$ is the best alternative.

\begin{tabular}{|c|c|c|c|c|c|c|}
\hline \multicolumn{2}{|c|}{$\begin{array}{l}\text { Linguistic variables for rating the } \\
\text { suppliers }\end{array}$} & \multicolumn{4}{|c|}{ Linguistic variables for the weighting of each criterion } & \multirow{2}{*}{$\begin{array}{l}\text { Interval values for } \\
\text { linguistic } \\
\text { variables } \\
\text { Interval data } \\
\text { at } 0.3 \alpha\end{array}$} \\
\hline $\begin{array}{l}\text { Linguistic } \\
\text { variables }\end{array}$ & $\begin{array}{l}\text { Triangular fuzzy } \\
\text { number for fuzzy } \\
\text { COPRAS and } \\
\text { fuzzy } \\
\text { MULTIMOORA }\end{array}$ & $\begin{array}{l}\text { Linguistic variables } \\
\text { (priority weights) }\end{array}$ & $\begin{array}{l}\text { Triangular fuzzy } \\
\text { numbers of the } \\
\text { fuzzy BWM } \\
\text { (Guo } \\
\text { and Zhao 2017) }\end{array}$ & $\begin{array}{l}\text { Linguistic variables } \\
\text { (priority weights) }\end{array}$ & $\begin{array}{l}\text { Triangular fuzzy } \\
\text { number for fuzzy } \\
\text { Shannon }\end{array}$ & \\
\hline Very low (VL) & $(0,0,0.25)$ & Equally importance (EI) & $(1,1,1)$ & Unimportant (UI) & $(0,0,0.2)$ & {$[0,0.17]$} \\
\hline Low (L) & $(0,0.25,0.5)$ & Weakly importance (WI) & $(2 / 3,1,3 / 2)$ & $\begin{array}{l}\text { Slightly important } \\
\text { (SI) }\end{array}$ & $(0,0.2,0.4)$ & {$[0.07,0.42]$} \\
\hline Medium (M) & $(0.25,0.5,0.75)$ & Fairly importance (FI) & $(3 / 2,2,5 / 2)$ & Fairly important (FI) & $(0.2,0.4,0.6)$ & {$[0.32,0.67]$} \\
\hline $\operatorname{High}(\mathrm{H})$ & $(0.5,0.75,0.1)$ & Very importance (VI) & $(5 / 2,3,7 / 2)$ & Important (I) & $(0.4,0.6,0.8)$ & {$[0.57,0.92]$} \\
\hline Very high (VH) & $(0.75,1,1)$ & $\begin{array}{l}\text { Absolutely importance } \\
\text { (AI) }\end{array}$ & $(7 / 2,4,9 / 2)$ & Very important (VI) & $(0.6,0.8,1)$ & {$[0.82,1]$} \\
\hline
\end{tabular}

Table 3 Linguistic variables for fuzzy COPRAS, fuzzy MULTIMOORA, fuzzy BWM, and Shannon's entropy methods 
Table 4 Interval DM for the fuzzy Shannon's entropy method

Criteria DM1 DM2 DM3 DM4 DM5 DM6 Aggregate DMs

\begin{tabular}{llllllll}
\hline $\mathrm{C} 11$ & $\mathrm{H}$ & $\mathrm{VH}$ & $\mathrm{H}$ & $\mathrm{VH}$ & $\mathrm{VH}$ & $\mathrm{VH}$ & {$[0.73660 .9733]$} \\
$\mathrm{C} 12$ & $\mathrm{VH}$ & $\mathrm{I}$ & $\mathrm{M}$ & $\mathrm{VH}$ & $\mathrm{H}$ & $\mathrm{H}$ & {$[0.61160 .9066]$} \\
$\mathrm{C} 13$ & $\mathrm{H}$ & $\mathrm{VI}$ & $\mathrm{H}$ & $\mathrm{H}$ & $\mathrm{H}$ & $\mathrm{H}$ & {$[0.570 .92]$} \\
$\mathrm{C} 14$ & $\mathrm{H}$ & $\mathrm{VH}$ & $\mathrm{H}$ & $\mathrm{VH}$ & $\mathrm{VH}$ & $\mathrm{VH}$ & {$[0.73660 .9733]$} \\
$\mathrm{C} 21$ & $\mathrm{VH}$ & $\mathrm{VH}$ & $\mathrm{VH}$ & $\mathrm{H}$ & $\mathrm{H}$ & $\mathrm{H}$ & {$[0.6590 .96]$} \\
$\mathrm{C} 22$ & $\mathrm{VH}$ & $\mathrm{VH}$ & $\mathrm{H}$ & $\mathrm{H}$ & $\mathrm{H}$ & $\mathrm{H}$ & {$[0.65330 .946]$} \\
$\mathrm{C} 23$ & $\mathrm{VH}$ & $\mathrm{VH}$ & $\mathrm{VH}$ & $\mathrm{VH}$ & $\mathrm{H}$ & $\mathrm{VH}$ & {$[0.77830 .9866]$} \\
$\mathrm{C} 31$ & $\mathrm{H}$ & $\mathrm{H}$ & $\mathrm{H}$ & $\mathrm{H}$ & $\mathrm{H}$ & $\mathrm{H}$ & {$[0.570 .92]$} \\
$\mathrm{C} 32$ & $\mathrm{M}$ & $\mathrm{H}$ & $\mathrm{H}$ & $\mathrm{M}$ & $\mathrm{H}$ & $\mathrm{H}$ & {$[0.48660 .84]$} \\
$\mathrm{C} 33$ & $\mathrm{VH}$ & $\mathrm{H}$ & $\mathrm{H}$ & $\mathrm{H}$ & $\mathrm{H}$ & $\mathrm{VH}$ & {$[0.65330 .9466]$} \\
$\mathrm{C} 34$ & $\mathrm{H}$ & $\mathrm{H}$ & $\mathrm{VH}$ & $\mathrm{VH}$ & $\mathrm{H}$ & $\mathrm{H}$ & {$[0.65330 .9466]$} \\
$\mathrm{C} 41$ & $\mathrm{VH}$ & $\mathrm{H}$ & $\mathrm{VH}$ & $\mathrm{H}$ & $\mathrm{H}$ & $\mathrm{VH}$ & {$[0.6950 .96]$} \\
$\mathrm{C} 42$ & $\mathrm{H}$ & $\mathrm{M}$ & $\mathrm{H}$ & $\mathrm{M}$ & $\mathrm{H}$ & $\mathrm{H}$ & {$[0.48660 .84]$} \\
$\mathrm{C} 43$ & $\mathrm{VH}$ & $\mathrm{H}$ & $\mathrm{H}$ & $\mathrm{H}$ & $\mathrm{H}$ & $\mathrm{M}$ & {$[0.570 .8933]$} \\
$\mathrm{C} 11$ & $\mathrm{H}$ & $\mathrm{VH}$ & $\mathrm{H}$ & $\mathrm{H}$ & $\mathrm{H}$ & $\mathrm{H}$ & {$[0.61160 .9333]$} \\
\end{tabular}

Note: Green supplier selection and evaluation (GSSE)

\section{Fuzzy MULTIMOORA}

The MULTIMOORA approach is a combination of multiobjective optimization with ratio analysis (MOORA) and the full multiplicative form (FMF) of multiple objectives. MULTIMOORA is a vigorous method in multiple objective optimizations (Brauers and Zavadskas 2011). Previous studies had applied the MULTIMOORA approach in various disciplines such as risk assessment (Fattahi and Khalilzadeh 2018), project management initiatives (Dorfeshan et al. 2018), automobile selection (Wu et al. 2017), choosing home structure

Table 5 Final weights for the fuzzy Shannon entropy's method

\begin{tabular}{|c|c|c|c|c|}
\hline Criteria & {$\left[\begin{array}{ll}h^{1} & h^{u}\end{array}\right]$} & {$\left[\begin{array}{ll}d^{1} & d^{u}\end{array}\right]$} & {$\left[\begin{array}{ll}w^{1} & W^{u}\end{array}\right]$} & $w_{i}^{\prime}$ \\
\hline $\mathrm{C} 11$ & {$\left[\begin{array}{ll}0.0573 & 0.0686\end{array}\right]$} & {$\left[\begin{array}{ll}0.9313 & 0.9426\end{array}\right]$} & {$\left[\begin{array}{lll}0.0654 & 0.0673\end{array}\right]$} & 0.0664 \\
\hline $\mathrm{C} 12$ & {$\left[\begin{array}{lll}0.0506 & 0.0656\end{array}\right]$} & {$\left[\begin{array}{lll}0.9343 & 0.9493\end{array}\right]$} & {$\left[\begin{array}{lll}0.0656 & 0.0678\end{array}\right]$} & 0.0667 \\
\hline $\mathrm{C} 13$ & {$\left[\begin{array}{lll}0.0482 & 0.0662\end{array}\right]$} & {$\left[\begin{array}{lll}0.9337 & 0.9517\end{array}\right]$} & {$\left[\begin{array}{lll}0.0656 & 0.0679\end{array}\right]$} & 0.0668 \\
\hline $\mathrm{C} 14$ & {$\left[\begin{array}{ll}0.0573 & 0.0686\end{array}\right]$} & {$\left[\begin{array}{lll}0.9319 & 0.9426\end{array}\right]$} & {$\left[\begin{array}{lll}0.0654 & 0.0673\end{array}\right]$} & 0.0664 \\
\hline $\mathrm{C} 21$ & {$\left[\begin{array}{ll}0.0551 & 0.0686\end{array}\right]$} & {$\left[\begin{array}{lll}0.9319 & 0.9448\end{array}\right]$} & {$\left[\begin{array}{lll}0.0655 & 0.0676\end{array}\right]$} & 0.0665 \\
\hline $\mathrm{C} 22$ & {$\left[\begin{array}{lll}0.0529 & 0.0674\end{array}\right]$} & {$\left[\begin{array}{lll}0.9325 & 0.9470\end{array}\right]$} & {$\left[\begin{array}{lll}0.0655 & 0.0676\end{array}\right]$} & 0.0666 \\
\hline $\mathrm{C} 23$ & {$\left[\begin{array}{lll}0.0594 & 0.0691\end{array}\right]$} & {$\left[\begin{array}{lll}0.9308 & 0.9405\end{array}\right]$} & {$\left[\begin{array}{lll}0.0654 & 0.0671\end{array}\right]$} & 0.0663 \\
\hline C31 & {$\left[\begin{array}{lll}0.0482 & 0.0662\end{array}\right]$} & {$\left[\begin{array}{lll}0.9337 & 0.9517\end{array}\right]$} & {$\left[\begin{array}{lll}0.0656 & 0.0679\end{array}\right]$} & 0.0668 \\
\hline $\mathrm{C} 32$ & {$\left[\begin{array}{lll}0.0432 & 0.0624\end{array}\right]$} & {$\left[\begin{array}{lll}0.9375 & 0.9567\end{array}\right]$} & {$\left[\begin{array}{lll}0.0659 & 0.0683\end{array}\right]$} & 0.0671 \\
\hline $\mathrm{C} 33$ & {$\left[\begin{array}{lll}0.0529 & 0.0674\end{array}\right]$} & {$\left[\begin{array}{lll}0.9325 & 0.9470\end{array}\right]$} & {$\left[\begin{array}{lll}0.0655 & 0.0676\end{array}\right]$} & 0.0666 \\
\hline $\mathrm{C} 34$ & {$\left[\begin{array}{lll}0.0529 & 0.0674\end{array}\right]$} & {$\left[\begin{array}{lll}0.9325 & 0.9470\end{array}\right]$} & {$\left[\begin{array}{lll}0.0655 & 0.0676\end{array}\right]$} & 0.0666 \\
\hline $\mathrm{C} 41$ & {$\left[\begin{array}{ll}0.0551 & 0.0680\end{array}\right]$} & {$\left[\begin{array}{lll}0.9319 & 0.9448\end{array}\right]$} & {$\left[\begin{array}{lll}0.0655 & 0.0674\end{array}\right]$} & 0.0665 \\
\hline $\mathrm{C} 42$ & {$\left[\begin{array}{lll}0.0432 & 0.0624\end{array}\right]$} & {$\left[\begin{array}{lll}0.9375 & 0.9567\end{array}\right]$} & {$\left[\begin{array}{lll}0.0659 & 0.0683\end{array}\right]$} & 0.0671 \\
\hline $\mathrm{C} 43$ & {$\left[\begin{array}{lll}0.0482 & 0.0649\end{array}\right]$} & {$\left[\begin{array}{lll}0.9350 & 0.9517\end{array}\right]$} & {$\left[\begin{array}{lll}0.0657 & 0.0679\end{array}\right]$} & 0.0668 \\
\hline
\end{tabular}

and fabric (Zavadskas et al. 2017), logistics (Awasthi and Baležentis 2017), supplier selection (Liu et al. 2018a), recycling (Ding and Zhong 2018), entertainment (Wu et al. 2018), automobile design (Liu et al. 2018b), ERP (Tian et al. 2017), robotics (You et al. 2018), agriculture (Hafezalkotob et al. 2018), and housing industry (Zavadskas et al. 2017).

\section{Fuzzy MOORA}

Brauers and Zavadskas (2006) initially recommended the MOORA for improving two or more contradicting attributes that are bound to specific limitations. The MOORA approach is a multicriteria decision-making method commonly used to solve business challenges such as manufacturing, gas and oil industry, process design, or every flawless decision that considers several other contradicting attributes (Akkaya et al. 2015). According to Ceballos et al. (2016), the MOORA method builds a ranking system that is resorted to three computations: the reference point (RP), the ratio system, and the FMF of multiple objectives (Ceballos et al. 2016). The fuzzy MOORA approach as a multicriteria decision-making technique for privatization research in a subsistence economy is proposed by Brauers and Zavadskas (2006). The stages of the fuzzy ratio approach used in this research are identical in the previous applications of this method by Karande and Chakraborty (2012), Gupta et al. (2017), and Akkaya et al. (2015):

Step 1: In this stage, a DM is formed using triangular fuzzy numbers:

$$
\widetilde{X}=\left[\begin{array}{cccc}
{\left[x_{11}^{l}, x_{11}^{m}, x_{11}^{u}\right]} & {\left[x_{12}^{l}, x_{12}^{m}, x_{12}^{u}\right]} & \ldots & {\left[x_{1 n}^{l}, x_{1 n}^{m}, x_{1 n}^{u}\right]} \\
\cdot & \cdot & \ldots & \cdot \\
\cdot & \cdot & \cdots & \vdots \\
{\left[x_{m 1}^{l}, x_{m 1}^{m}, x_{m 1}^{u}\right]} & {\left[x_{m 2}^{l}, x_{m 2}^{m}, x_{m 2}^{u}\right]} & \ldots & {\left[x_{m n}^{l}, x_{m n}^{m}, x_{m n}^{u}\right]}
\end{array}\right]
$$

Step 2: In this stage, the DM is changed to a normalized fuzzy DM (FDM) utilizing Eqs. (25), (26), and (27):

$$
\begin{aligned}
& \text { As } \widetilde{X}_{i j}^{*}=\left(x_{i j}^{l *}, x_{i j}^{m^{*}}, x_{i j}^{u *}\right) \text { and } \forall i, j, \\
& x_{i j}^{l^{*}}=x_{i j}^{l} / \sqrt{\sum_{i=1}^{m}\left[\left(x_{i j}^{l}\right)^{2}+\left(x_{i j}^{m}\right)^{2}+\left(x_{i j}^{u}\right)^{2}\right]} \\
& x_{i j}^{m^{*}}=x_{i j}^{m} / \sqrt{\sum_{i=1}^{m}\left[\left(x_{i j}^{l}\right)^{2}+\left(x_{i j}^{m}\right)^{2}+\left(x_{i j}^{u}\right)^{2}\right]} \\
& x_{i j}^{u *}=x_{i j}^{u} / \sqrt{\sum_{i=1}^{m}\left[\left(x_{i j}^{l}\right)^{2}+\left(x_{i j}^{m}\right)^{2}+\left(x_{i j}^{u}\right)^{2}\right]}
\end{aligned}
$$


Table 6 Linguistic terms for fuzzy preferences of the criteria by experts

\begin{tabular}{llllll}
\hline & & \multicolumn{2}{l}{ Criteria } & & \\
\cline { 3 - 5 } Best criterion & Worst criterion & $\mathrm{C} 1$ & $\mathrm{C} 2$ & $\mathrm{C} 3$ & $\mathrm{C} 4$ \\
\hline $\mathrm{C} 1$ & - & $(1,1,1)$ & $(2.5,3,3.5)$ & $(1.5,2,2.5)$ & $(0.67,1,1.5)$ \\
- & $\mathrm{C} 2$ & $(2.5,3,3.5)$ & $(1,1,1)$ & $(0.67,1,1.5)$ & $(1.5,2,2.5)$ \\
\hline
\end{tabular}

Step 3: In this stage, the weighted normalized FDM is determined by using Eqs. (28), (29), and (31):

$$
\begin{aligned}
& V_{i j}=\left(v_{i j}^{l}, v_{i j}^{m}, v_{i j}^{u}\right) ; \\
& v_{i j}^{l}=w_{j} \chi_{i j}^{l^{*}} \\
& v_{i j}^{m}=w_{j} \chi_{i j}^{m^{*}} \\
& v_{i j}^{u}=w_{j} \chi_{i j}^{u^{*}}
\end{aligned}
$$

This research used the weights calculated previously by the fuzzy Shannon entropy to compute the weighted normalized FDM.

Step 4: In this stage, Eq. (31) is used to compute the normalized performance measures where the total cost measures are deducted from overall benefit measures as follows:

$$
\begin{gathered}
V_{i j}=\left(v_{i j}^{l}, v_{i j}^{m}, v_{i j}^{u}\right) ; \\
y_{i}=\sum_{j=1}^{g} V_{i j}-\sum_{j=g+1}^{n} V_{i j}
\end{gathered}
$$

where $\sum_{j=1}^{g} V_{i j}$ shows the benefit measures (for $1, \ldots, g$ ) and $\sum_{j=g+1}^{n} V_{i j}$ indicates the cost measure (for $g+$
$1, \ldots, n)$, where $g$ and $(n-g)$ show the maximum and the minimum number of measures, respectively. For the benefit measures, the total ratings of an alternative can be computed for the low, center, and high limits of the triangular membership function, which are appended below:

$$
\begin{aligned}
& y_{i}^{+l}=\sum_{j=1}^{n} v_{i j}^{l} \mid j \in J^{\max } \\
& y_{i}^{+m}=\sum_{j=1}^{n} v_{i j}^{m} \mid j \in J^{\max } \\
& y_{i}^{+u}=\sum_{j=1}^{n} v_{i j}^{u} \mid j \in J^{\max }
\end{aligned}
$$

In addition, the cost measures are computed in the same way for the entire ratings of an objective, as shown below:

$y_{i}^{-l}=\sum_{j=1}^{n} v_{i j}^{l} \mid j \in J^{\max }$

$y_{i}^{-m}=\sum_{j=1}^{n} v_{i j}^{m} \mid j \in J^{\max }$

\begin{tabular}{|c|c|c|c|c|c|c|}
\hline & Best criterion & Worst criterion & Sub-criteria & & & \\
\hline \multirow[t]{3}{*}{$\mathrm{C} 1$} & & & $\mathrm{C} 11$ & $\mathrm{C} 12$ & $\mathrm{C} 13$ & $\mathrm{C} 14$ \\
\hline & $\mathrm{C} 11$ & - & $(1,1,1)$ & $(0.67,1,1.5)$ & $(2.5,3,3.5)$ & $(1.5,2,2.5)$ \\
\hline & & $\mathrm{C} 13$ & $(2.5,3,3.5)$ & $(1.5,2,2.5)$ & $(1,1,1)$ & $(0.67,1,1.5)$ \\
\hline \multirow[t]{3}{*}{$\mathrm{C} 2$} & & & $\mathrm{C} 21$ & $\mathrm{C} 22$ & $\mathrm{C} 23$ & \\
\hline & $\mathrm{C} 21$ & - & $(1,1,1)$ & $(2.5,3,3.5)$ & $(1.5,2,2.5)$ & \\
\hline & - & $\mathrm{C} 22$ & $(2.5,3,3.5)$ & $(1,1,1)$ & $(0.67,1,1.5)$ & \\
\hline \multirow[t]{3}{*}{$\mathrm{C} 3$} & & & $\mathrm{C} 31$ & $\mathrm{C} 32$ & $\mathrm{C} 33$ & $\mathrm{C} 34$ \\
\hline & $\mathrm{C} 31$ & - & $(1,1,1)$ & $(0.67,1,1.5)$ & $(2.5,3,3.5)$ & $(1.5,2,2.5)$ \\
\hline & - & $\mathrm{C} 33$ & $(2.5,3,3.5)$ & $(1.5,2,2.5)$ & $(1,1,1)$ & $(0.67,1,1.5)$ \\
\hline \multirow[t]{3}{*}{$\mathrm{C} 4$} & & & $\mathrm{C} 41$ & $\mathrm{C} 42$ & $\mathrm{C} 43$ & \\
\hline & $\mathrm{C} 42$ & - & $(1.5,2,2.5)$ & $(1,1,1)$ & $(0.67,1,1.5)$ & \\
\hline & - & $\mathrm{C} 41$ & $(1,1,1)$ & $(1.5,2,2.5)$ & $(0.67,1,1.5)$ & \\
\hline
\end{tabular}

$y_{i}^{-u}=\sum_{j=1}^{n} v_{i j}^{u} \mid j \in J^{\max }$

Step 5: In this stage, the entire performance index $\left(y_{i}\right)$ for each objective is identified by computing the
Table 7 Linguistic terms for fuzzy preferences of the subcriteria by experts 
Table 8 Weights of the sub-criteria determined by HFBWM

\begin{tabular}{llllllll}
\hline Sub-criteria & $\mathrm{C} 11$ & $\mathrm{C} 12$ & $\mathrm{C} 13$ & $\mathrm{C} 14$ & $\mathrm{C} 21$ & $\mathrm{C} 22$ & $\mathrm{C} 23$ \\
$G w_{S}{ }_{S}$ & 0.015852 & 0.012362 & 0.005945 & 0.007132 & 0.037442 & 0.013576 & 0.016744 \\
Sub-criteria & $\mathrm{C} 31$ & $\mathrm{C} 32$ & $\mathrm{C} 33$ & $\mathrm{C} 34$ & $\mathrm{C} 41$ & $\mathrm{C} 42$ & $\mathrm{C} 43$ \\
$G w_{S}^{j}$ & 0.012847 & 0.010018 & 0.004818 & 0.00578 & 0.026442 & 0.044879 \\
\hline
\end{tabular}

defuzzified boundaries of the total ratings of the benefit and cost measures for all the alternatives utilizing the vertex approach appended below:

$y_{i}=\left(y_{i}^{l}, y_{i}^{m}, y_{i}^{u}\right)$;

$B N P_{i}\left(y_{i}\right)=\frac{\left(y_{i}^{u}-y_{i}^{l}\right)+\left(y_{i}^{m}-y_{i}^{l}\right)}{3}+y_{i}^{l}$

within which Eq. (38) indicates the total performance value of the $i$-th alternative (objective).

Step 6: In this stage, the total performance index is arranged from high to low values, and this study ranks all the alternatives from the excellent to the inferior. Among the alternatives, the most preferred choice is the alternative with the highest total performance index.

\section{Fuzzy reference point method}

Equations (25), (26), and (27) compute the RP method. This method utilizes the normalized performance of the $i$-th objective on the $j$-th measure based on the aforementioned equations. In addition, a maximum measure RP is identified between the normalized performances as a non-subjective and feasible to the coordinates $\left(r_{j}\right)$. In Eq. (39), the minimummaximum metric formula is described, and previous research highlights that this is the appropriate formula for the RP (Adal and Ișik 2017) as follows:

$\left\{\begin{array}{l}\tilde{r}_{j}^{+}=\left(\max _{i} x_{i j}{ }^{l *}, \max _{i} x_{i j}{ }^{m^{*}}, \max _{i} x_{i j} u^{*}\right), j \leq g ; \text { for criteria to be maximized } \\ \left.\tilde{r}_{j}^{=}=\left(\min _{i} x_{i j}{ }^{l^{*}}, \min _{i} x_{i j}{ }^{m^{*}}, \min _{i} x_{i j}^{u^{*}}\right), j\right\rangle g ; \text { for criteria to be minimized }\end{array}\right.$

On condition that decision-makers decide to assign a higher value to a particular measure, Eq. (39) is recalculated through examining the weights of the measures as follows:

$\min _{i}\left(\max _{j} W_{j} \times\left|\widetilde{r}_{j}-\tilde{x}_{i j}^{*}\right|\right)$

The objectives are eventually ranked based on Eq. (38), and the most attractive objective is selected based on the lowest overall distance from the RPs (Adali and Iş1k 2017).

Table 9 Fuzzy DM results for each supplier

\begin{tabular}{|c|c|c|c|c|c|c|c|c|c|c|c|c|c|c|c|c|}
\hline \multirow[t]{2}{*}{ Criteria } & \multicolumn{16}{|c|}{ Supplier } \\
\hline & $\mathrm{S} 1$ & & & S2 & & & S3 & & & $\ldots$ & $\mathrm{S} 11$ & & & S12 & & \\
\hline $\mathrm{C} 11$ & 0.3125 & 0.5625 & 0.8125 & 0.0625 & 0.3125 & 0.5625 & 0.0625 & 0.3125 & 0.5625 & $\ldots$ & 0.375 & 0.625 & 0.875 & 0.25 & 0.5 & 0.75 \\
\hline $\mathrm{C} 12$ & 0.25 & 0.5 & 0.75 & 0.0625 & 0.1875 & 0.4375 & 0.125 & 0.375 & 0.625 & $\ldots$ & 0.75 & 1 & 1 & 0.3125 & 0.5625 & 0.8125 \\
\hline $\mathrm{C} 13$ & 0.1875 & 0.4375 & 0.6875 & 0.625 & 0.875 & 1 & 0.3125 & 0.5625 & 0.8125 & $\ldots$ & 0.125 & 0.375 & 0.625 & 0.125 & 0.375 & 0.625 \\
\hline $\mathrm{C} 14$ & 0.0625 & 0.3125 & 0.5625 & 0.5 & 0.75 & 1 & 0.25 & 0.5 & 0.75 & $\ldots$ & 0.0625 & 0.3125 & 0.5625 & 0.125 & 0.375 & 0.625 \\
\hline $\mathrm{C} 21$ & 0.3125 & 0.5625 & 0.8125 & 0.5 & 0.75 & 1 & 0.5 & 0.75 & 1 & $\ldots$ & 0.0625 & 0.25 & 0.5 & 0.0625 & 0.25 & 0.5 \\
\hline $\mathrm{C} 22$ & 0.375 & 0.625 & 0.875 & 0.625 & 0.875 & 1 & 0.4375 & 0.6875 & 0.9375 & $\ldots$ & 0.0625 & 0.25 & 0.5 & 0.0625 & 0.3125 & 0.5625 \\
\hline $\mathrm{C} 23$ & 0.375 & 0.625 & 0.875 & 0.5 & 0.75 & 1 & 0.4375 & 0.6875 & 0.9375 & $\ldots$ & 0.0625 & 0.25 & 0.5 & 0.125 & 0.375 & 0.625 \\
\hline $\mathrm{C} 31$ & 0.1875 & 0.4375 & 0.6875 & 0.5625 & 0.8125 & 1 & 0.375 & 0.625 & 0.875 & $\ldots$ & 0.0625 & 0.1875 & 0.4375 & 0.0625 & 0.1875 & 0.4375 \\
\hline $\mathrm{C} 32$ & 0.1875 & 0.4375 & 0.6875 & 0.625 & 0.875 & 1 & 0.25 & 0.5 & 0.75 & $\ldots$ & 0.1875 & 0.4375 & 0.6875 & 0.0625 & 0.25 & 0.5 \\
\hline $\mathrm{C} 33$ & 0.25 & 0.5 & 0.75 & 0.5 & 0.75 & 1 & 0.25 & 0.5 & 0.75 & $\ldots$ & 0.25 & 0.5 & 0.75 & 0.0625 & 0.25 & 0.5 \\
\hline C34 & 0.125 & 0.375 & 0.625 & 0.5 & 0.75 & 1 & 0.4375 & 0.6875 & 0.9375 & $\ldots$ & 0.1875 & 0.4375 & 0.6875 & 0.1875 & 0.4375 & 0.6875 \\
\hline C41 & 0.4375 & 0.6875 & 0.9375 & 0.0625 & 0.25 & 0.5 & 0.125 & 0.375 & 0.625 & $\ldots$ & 0.4375 & 0.6875 & 0.9375 & 0.5625 & 0.8125 & 1 \\
\hline $\mathrm{C} 42$ & 0.3125 & 0.5625 & 0.8125 & 0.0625 & 0.125 & 0.375 & 0.0625 & 0.3125 & 0.5625 & $\ldots$ & 0.4375 & 0.6875 & 0.9375 & 0.5 & 0.75 & 1 \\
\hline $\mathrm{C} 43$ & 0.1875 & 0.4375 & 0.6875 & 0.0625 & 0.125 & 0.375 & 0.0625 & 0.125 & 0.375 & $\ldots$ & 0.25 & 0.5 & 0.75 & 0.4375 & 0.6875 & 0.9375 \\
\hline
\end{tabular}


Table 10 Alternative rankings with fuzzy COPRAS-FShannon

\begin{tabular}{|c|c|c|c|c|c|c|c|c|c|c|c|c|}
\hline Supplier & $\tilde{p}_{j}$ & & & $\widetilde{R}_{j}$ & & & $\widetilde{Q}_{j}$ & & & Non-fuzzy $\widetilde{Q}_{j}$ & $K_{j}$ & $\begin{array}{l}\text { Fuzzy COPRAS } \\
\text { ranking }\end{array}$ \\
\hline 1 & 0.0383 & 0.0801 & 0.1219 & 0.0279 & 0.0511 & 0.0744 & 0.0572 & 0.1201 & 0.182 & 0.1198 & 0.5158 & 7 \\
\hline 2 & 0.0759 & 0.1105 & 0.1383 & 0.0048 & 0.0154 & 0.0346 & 0.1853 & 0.2436 & 0.2676 & 0.2322 & 1 & 1 \\
\hline 3 & 0.0589 & 0.0996 & 0.1404 & 0.0079 & 0.0272 & 0.0499 & 0.1252 & 0.1748 & 0.2301 & 0.1767 & 0.7611 & 2 \\
\hline 4 & 0.0438 & 0.0876 & 0.1314 & 0.017 & 0.0402 & 0.0645 & 0.0746 & 0.1385 & 0.2007 & 0.1379 & 0.5941 & 3 \\
\hline 5 & 0.0254 & 0.0711 & 0.1168 & 0.0318 & 0.0572 & 0.0826 & 0.0419 & 0.1069 & 0.1709 & 0.1066 & 0.4591 & 8 \\
\hline 6 & 0.0315 & 0.0705 & 0.1096 & 0.038 & 0.0597 & 0.0804 & 0.0453 & 0.1048 & 0.1652 & 0.1051 & 0.4527 & 9 \\
\hline 7 & 0.0634 & 0.0942 & 0.119 & 0.0291 & 0.0463 & 0.0617 & 0.0814 & 0.1384 & 0.1915 & 0.1371 & 0.5906 & 5 \\
\hline 8 & 0.0617 & 0.0934 & 0.1208 & 0.0282 & 0.0459 & 0.0609 & 0.0804 & 0.138 & 0.1942 & 0.1375 & 0.5925 & 4 \\
\hline 9 & 0.0212 & 0.0614 & 0.1016 & 0.0448 & 0.0671 & 0.085 & 0.033 & 0.0919 & 0.1543 & 0.093 & 0.4008 & 10 \\
\hline 10 & 0.0625 & 0.0929 & 0.1157 & 0.0321 & 0.049 & 0.0617 & 0.0789 & 0.1346 & 0.1882 & 0.1339 & 0.5768 & 6 \\
\hline 11 & 0.0203 & 0.0572 & 0.1 & 0.0429 & 0.0668 & 0.0858 & 0.0325 & 0.0878 & 0.1521 & 0.0908 & 0.3912 & 11 \\
\hline 12 & 0.0174 & 0.0559 & 0.1007 & 0.0411 & 0.066 & 0.0897 & 0.0302 & 0.0869 & 0.1506 & 0.0892 & 0.3844 & 12 \\
\hline
\end{tabular}

\section{Fuzzy full multiplicative form}

The third phase of the MULTIMOORA approach is FMF. This approach was initially proposed by Miller and Starr (1969), and it is both consisted of max and min values of a completely multiplicative utility formula. The key features of the FMF include not using attribute weights, being non-additive, and non-linear (Adalı and Ișık 2017). The appended formula, based on the guidelines of Hafezalkotob et al. (2019), calculates the FMF's utility function as a fraction of the weighted normalized alternatives' ratings on the benefit measures over the weighted normalized alternatives' ratings on the cost measures:

$\widetilde{U}_{i}^{\prime}=\frac{\widetilde{A}_{i}}{\widetilde{B}_{i}}$

where $\widetilde{A}_{i}=\left(A_{i 1}, A_{i 2}, A_{i 3}\right)=\prod_{j=1}^{g}\left(x_{i j}^{*}\right)^{w_{j}}$ represents the result of the number of objectives of the $i$-th alternative to get augmented with terms of $g=1,2, \ldots, n$ and $\widetilde{B}_{i}=$
$\left(B_{i 1}, B_{i 2}, B_{i 3}\right)=\prod_{j=g+1}^{m}\left(x_{i j}^{*}\right)^{w_{j}}$ represents the result of the objectives for the $i$-th alternative to get reduced with the condition of $n-g$. In Eq. (41), propagating the weights with the normalized ratings is conducive to a similar outcome in which no weights are evaluated. Therefore, weights need to be referred to as the exponents of Eq. (41) in the FMF. Since the result of the overall utility function $\left(\widetilde{U}_{i}\right)$ has a fuzzy digit, defuzzification is required based on Eq. (38) to grade each of the alternatives. According to Akkaya et al. (2015), the rank of each of the $i$-th alternative is greater if the $B N P_{i}$ receives a greater value.

According to the FMF, the most advantageous alternative contains the maximum utility (which is retrieved from Eq. (41)) $\left(\widetilde{U}_{i}^{\prime}\right)$, and the ranking procedure for this approach is computed in the following formula:

$R_{F M F}=\left\{A_{i \mid \max u_{i i}}>\ldots>A_{i \mid \max u_{i i}}\right\}$.

Table 11 Alternative rankings with fuzzy COPRAS-HFBWM

\begin{tabular}{|c|c|c|c|c|c|c|c|c|c|c|c|c|}
\hline Supplier & $\tilde{p}_{j}$ & & & $\widetilde{R}_{j}$ & & & $\widetilde{Q}_{j}$ & & & Non-fuzzy $\widetilde{Q}_{j}$ & $K_{j}$ & $\begin{array}{l}\text { Fuzzy COPRAS } \\
\text { ranking }\end{array}$ \\
\hline 1 & 0.0086 & 0.0166 & 0.0245 & 0.0112 & 0.0205 & 0.0298 & 0.0158 & 0.0317 & 0.0482 & 0.0319 & 0.4489 & 7 \\
\hline 2 & 0.0142 & 0.0208 & 0.0264 & 0.0019 & 0.0055 & 0.0132 & 0.0561 & 0.0773 & 0.0798 & 0.0711 & 1 & 1 \\
\hline 3 & 0.0127 & 0.0205 & 0.0282 & 0.0029 & 0.0103 & 0.0194 & 0.0403 & 0.0506 & 0.0646 & 0.0518 & 0.7293 & 2 \\
\hline 4 & 0.0108 & 0.0191 & 0.0275 & 0.0066 & 0.0158 & 0.0256 & 0.0229 & 0.0387 & 0.0551 & 0.0389 & 0.5475 & 3 \\
\hline 5 & 0.005 & 0.0137 & 0.0224 & 0.0139 & 0.0241 & 0.0344 & 0.0108 & 0.0265 & 0.0429 & 0.0267 & 0.3763 & 8 \\
\hline 6 & 0.0053 & 0.0128 & 0.0202 & 0.0159 & 0.0246 & 0.0328 & 0.0104 & 0.0254 & 0.0418 & 0.0258 & 0.3637 & 9 \\
\hline 7 & 0.011 & 0.0169 & 0.0221 & 0.0105 & 0.0174 & 0.0239 & 0.0187 & 0.0347 & 0.0516 & 0.035 & 0.4924 & 5 \\
\hline 8 & 0.0112 & 0.0173 & 0.0229 & 0.0096 & 0.0167 & 0.0232 & 0.0196 & 0.0358 & 0.0533 & 0.0363 & 0.5104 & 4 \\
\hline 9 & 0.0039 & 0.0116 & 0.0193 & 0.0192 & 0.0281 & 0.0346 & 0.0082 & 0.0226 & 0.0397 & 0.0235 & 0.3305 & 10 \\
\hline 10 & 0.0113 & 0.0171 & 0.0218 & 0.0114 & 0.0182 & 0.024 & 0.0184 & 0.0342 & 0.0512 & 0.0346 & 0.4868 & 6 \\
\hline 11 & 0.003 & 0.0095 & 0.0176 & 0.0157 & 0.0253 & 0.034 & 0.0081 & 0.0217 & 0.0384 & 0.0227 & 0.3201 & 11 \\
\hline 12 & 0.0029 & 0.01 & 0.0185 & 0.018 & 0.028 & 0.0375 & 0.0074 & 0.0211 & 0.0373 & 0.0219 & 0.3087 & 12 \\
\hline
\end{tabular}


Table 12 Alternative rankings with the fuzzy ratio method-FShannon

\begin{tabular}{|c|c|c|c|c|c|c|c|c|c|c|c|}
\hline \multirow[t]{3}{*}{ Supplier } & \multicolumn{9}{|c|}{$y_{i}=\sum_{j=1}^{g} \tilde{v}_{i j}-\sum_{j=g+1}^{n} \tilde{v}_{i j}$} & \multirow[t]{3}{*}{$B N P_{i}$} & \multirow[t]{3}{*}{$\begin{array}{l}\text { Fuzzy } \\
\text { ratio ranking }\end{array}$} \\
\hline & \multicolumn{3}{|c|}{ Benefits } & \multicolumn{3}{|l|}{ Cost } & \multicolumn{3}{|l|}{$y_{i}$} & & \\
\hline & $l$ & $m$ & $u$ & $l$ & $m$ & $u$ & $y_{i}^{l}$ & $y_{i}^{m}$ & $y_{i}^{u}$ & & \\
\hline S1 & 0.1443 & 0.3155 & 0.4867 & 0.0965 & 0.1799 & 0.2633 & -0.119 & 0.1356 & 0.3902 & 0.1356 & 7 \\
\hline $\mathrm{S} 2$ & 0.2355 & 0.3433 & 0.431 & 0.0434 & 0.1296 & 0.3032 & -0.0677 & 0.2137 & 0.3875 & 0.1778 & 1 \\
\hline $\mathrm{S} 3$ & 0.1906 & 0.3273 & 0.4641 & 0.0459 & 0.153 & 0.2914 & -0.1008 & 0.1744 & 0.4182 & 0.1639 & 2 \\
\hline S4 & 0.1487 & 0.3166 & 0.4844 & 0.0694 & 0.1704 & 0.277 & -0.1283 & 0.1461 & 0.415 & 0.1443 & 6 \\
\hline S5 & 0.1056 & 0.3049 & 0.5042 & 0.0987 & 0.1804 & 0.2621 & -0.1565 & 0.1245 & 0.4055 & 0.1245 & 9 \\
\hline S6 & 0.1293 & 0.3109 & 0.4925 & 0.1161 & 0.1852 & 0.2513 & -0.1221 & 0.1257 & 0.3765 & 0.1267 & 8 \\
\hline S7 & 0.2275 & 0.3417 & 0.4356 & 0.1156 & 0.1864 & 0.2506 & -0.0231 & 0.1553 & 0.32 & 0.1507 & 4 \\
\hline S8 & 0.2219 & 0.3387 & 0.4411 & 0.1108 & 0.1858 & 0.2522 & -0.0303 & 0.1528 & 0.3303 & 0.1509 & 3 \\
\hline S9 & 0.1008 & 0.3033 & 0.5059 & 0.1254 & 0.1898 & 0.243 & -0.1422 & 0.1136 & 0.3805 & 0.1173 & 10 \\
\hline S10 & 0.2284 & 0.3436 & 0.4331 & 0.122 & 0.1899 & 0.2439 & -0.0156 & 0.1537 & 0.3111 & 0.1498 & 5 \\
\hline S11 & 0.0963 & 0.2862 & 0.5157 & 0.1181 & 0.1878 & 0.2471 & -0.1508 & 0.0984 & 0.3976 & 0.1151 & 11 \\
\hline $\mathrm{S} 12$ & 0.086 & 0.2833 & 0.5201 & 0.1129 & 0.1845 & 0.2532 & -0.1671 & 0.0987 & 0.4072 & 0.1129 & 12 \\
\hline
\end{tabular}

\section{Final ranking}

The trio approaches of the MULTIMOORA method are equally important. Several approaches are applied to combine the rankings of the three supporting approaches. The final ranking of this research (in terms of measures used) is rooted in the dominance theory. This theory is a popular ranking aggregation method in MULTIMOORA related research (Hafezalkotob et al. 2019). As suggested by previous research, to get the final ranking of the measures, transitiveness principles, general dominance approaches, and absolute dominance are applied (Brauers and Zavadskas 2011).

\section{Fuzzy TOPSIS}

Hwang and Yoon (1981) proposed the TOPSIS method as an MCDM technique to rank alternatives by considering positive and negative ideal solutions. Chen (2000) was the first to extend TOPSIS into a fuzzy environment (Tavana et al. 2016a, b). We implement the fuzzy TOPSIS extension developed by Sun (2010), whose steps can be summarized as follows:

Step 1: Determine the fuzzy decision matrix.

Step 2: Calculate the normalized fuzzy decision matrix using Eqs. (43) and (44) below:

Table 13 Alternative rankings with the fuzzy ratio method-HFBWM

\begin{tabular}{|c|c|c|c|c|c|c|c|c|c|c|c|}
\hline \multirow[t]{3}{*}{ Supplier } & \multicolumn{9}{|c|}{$y_{i}=\sum_{j=1}^{g} \tilde{v}_{i j}-\sum_{j=g+1}^{n} \tilde{v}_{i j}$} & \multirow[t]{3}{*}{$B N P_{i}$} & \multirow[t]{3}{*}{ Fuzzy ratio ranking } \\
\hline & \multicolumn{3}{|c|}{ Benefits } & \multicolumn{3}{|l|}{ Cost } & \multicolumn{3}{|l|}{$y_{i}$} & & \\
\hline & $l$ & $m$ & $u$ & $l$ & $m$ & $u$ & $y_{i}^{l}$ & $y_{i}^{m}$ & $y_{i}^{u}$ & & \\
\hline S1 & 0.031 & 0.061 & 0.091 & 0.039 & 0.072 & 0.106 & -0.075 & -0.011 & 0.053 & -0.011 & 7 \\
\hline S2 & 0.044 & 0.065 & 0.083 & 0.018 & 0.049 & 0.123 & -0.078 & 0.016 & 0.064 & 0.001 & 1 \\
\hline $\mathrm{S} 3$ & 0.039 & 0.063 & 0.087 & 0.018 & 0.06 & 0.118 & -0.079 & 0.003 & 0.069 & -0.002 & 2 \\
\hline S4 & 0.032 & 0.061 & 0.09 & 0.028 & 0.068 & 0.111 & -0.079 & -0.007 & 0.062 & -0.008 & 3 \\
\hline S5 & 0.021 & 0.058 & 0.096 & 0.042 & 0.073 & 0.104 & -0.084 & -0.015 & 0.054 & -0.015 & 8 \\
\hline S6 & 0.023 & 0.059 & 0.095 & 0.047 & 0.075 & 0.1 & -0.077 & -0.016 & 0.047 & -0.015 & 9 \\
\hline S7 & 0.041 & 0.064 & 0.085 & 0.044 & 0.074 & 0.102 & -0.061 & -0.01 & 0.041 & -0.01 & 5 \\
\hline S8 & 0.041 & 0.064 & 0.085 & 0.041 & 0.073 & 0.104 & -0.063 & -0.01 & 0.044 & -0.009 & 4 \\
\hline S9 & 0.019 & 0.058 & 0.097 & 0.052 & 0.077 & 0.096 & -0.077 & -0.019 & 0.044 & -0.017 & 10 \\
\hline $\mathrm{S} 10$ & 0.043 & 0.065 & 0.084 & 0.046 & 0.075 & 0.101 & -0.058 & -0.01 & 0.038 & -0.01 & 6 \\
\hline S11 & 0.016 & 0.052 & 0.1 & 0.045 & 0.074 & 0.101 & -0.086 & -0.022 & 0.055 & -0.018 & 11 \\
\hline S12 & 0.015 & 0.053 & 0.1 & 0.047 & 0.075 & 0.101 & -0.085 & -0.022 & 0.053 & -0.018 & 12 \\
\hline
\end{tabular}


Table 14 Alternative rankings with fuzzy RP-FShannon

\begin{tabular}{|c|c|c|c|c|c|}
\hline Supplier & \multicolumn{3}{|c|}{$\left(\max _{j} W_{j} \times\left|\widetilde{r}_{j}-\widetilde{x}_{i j}^{*}\right|\right)$} & $B N P_{i}$ & $\begin{array}{l}\text { Fuzzy reference point } \\
\text { ranking }\end{array}$ \\
\hline S1 & 0.0137 & 0.0155 & 0.0049 & 0.0124 & 4 \\
\hline S2 & 0.0022 & 0 & 0.0191 & 0.0053 & 1 \\
\hline S3 & 0.0048 & 0.0078 & 0.0147 & 0.0088 & 2 \\
\hline S4 & 0.0062 & 0.0124 & 0.0119 & 0.0107 & 3 \\
\hline S5 & 0.0156 & 0.0159 & 0.0038 & 0.0128 & 5 \\
\hline S6 & 0.0163 & 0.0178 & 0.004 & 0.0139 & 7 \\
\hline S7 & 0.0203 & 0.0125 & 0.0058 & 0.0128 & 8 \\
\hline S8 & 0.0203 & 0.0125 & 0.0058 & 0.0128 & 9 \\
\hline S9 & 0.0195 & 0.02 & 0 & 0.0149 & 11 \\
\hline S10 & 0.022 & 0.0137 & 0.0038 & 0.0133 & 10 \\
\hline S11 & 0.0248 & 0.0156 & 0 & 0.014 & 12 \\
\hline $\mathrm{S} 12$ & 0.0184 & 0.0164 & 0.0021 & 0.0134 & 6 \\
\hline
\end{tabular}

$$
\begin{aligned}
& \tilde{R}=\left[\tilde{r}_{i j}\right]_{m \times n} \\
& \tilde{r}_{i j}=\left(\frac{l_{i j}}{u_{i j}^{+}}, \frac{m_{i j}}{u_{i j}^{+}}, \frac{u_{i j}}{u_{i j}^{+}}\right) \text {and } u_{i j}^{+}=\max u_{i j} \text { (benefit criteria) }
\end{aligned}
$$

$$
\tilde{r}_{i j}=\left(\frac{l_{j}^{-}}{u_{i j}}, \frac{l_{j}^{-}}{m_{i j}}, \frac{l_{j}^{-}}{l_{i j}}\right) \text { and } l_{j}^{-}=\min l_{i j}(\cos t \text { criteria })
$$

Step 3: Calculate the weighted normalized fuzzy decision matrix.

Step 4: Calculate the fuzzy positive ideal solution and the fuzzy negative ideal solution.
Step 5: Calculate the fuzzy positive and fuzzy negative distances $\widetilde{d}_{i}^{+}$and $\widetilde{d}_{i}^{-}$for the different alternatives.

Step 6: Calculate the closeness coefficients by applying Eq. (45) below:

$$
C C_{i}=\frac{d_{i}^{-}}{d_{i}^{-}+d_{i}^{+}}
$$

\section{Consensus ranking: maximize agreement heuristic}

In mathematics, the term consensus is ambiguous, susceptible to a myriad of explanations, and Emond and Mason (2002) indicate that little is known about consensus ranking. Beck and Lin (1983) showed that the maximization of rater agreement is considered as a rational measure for a consensus function, and they proposed the maximize agreement heuristic (MAH) method for representing consensus or collective agreement in decision-making problems. In ranking the ob-

\begin{tabular}{|c|c|c|c|c|c|}
\hline Supplier & $\left(\max _{j}\right.$ & & & $B N P_{i}$ & $\begin{array}{l}\text { Fuzzy reference point } \\
\text { ranking }\end{array}$ \\
\hline S1 & 0.009 & 0.01 & 0.003 & 0.008 & 7 \\
\hline S2 & 0.003 & 0 & 0.01 & 0.003 & 1 \\
\hline S3 & 0 & 0.008 & 0.007 & 0.006 & 2 \\
\hline S4 & 0.003 & 0.009 & 0.006 & 0.007 & 3 \\
\hline S5 & 0.01 & 0.011 & 0.003 & 0.009 & 8 \\
\hline S6 & 0.012 & 0.011 & 0.001 & 0.009 & 10 \\
\hline S7 & 0.008 & 0.01 & 0.004 & 0.008 & 5 \\
\hline S8 & 0.008 & 0.01 & 0.004 & 0.008 & 4 \\
\hline S9 & 0.014 & 0.012 & 0 & 0.009 & 12 \\
\hline S10 & 0.009 & 0.01 & 0.003 & 0.008 & 6 \\
\hline S11 & 0.011 & 0.011 & 0.002 & 0.009 & 9 \\
\hline $\mathrm{S} 12$ & 0.012 & 0.011 & 0.001 & 0.009 & 11 \\
\hline
\end{tabular}
jects, they also show how agreement and disagreement are achieved in the final consensus ranking (FCR). This study

Table 15 Alternative rankings with fuzzy RP-HFBWM 
Table 16 Alternative rankings with the fuzzy full multiplicative form-FShannon

\begin{tabular}{|c|c|c|c|c|c|c|c|c|c|c|}
\hline Supplier & $\widetilde{A_{i}}$ & & & $\widetilde{B}_{i}$ & & & $\begin{array}{l}\text { Non-fuzzy } \\
\widetilde{A}_{i}\end{array}$ & $\begin{array}{l}\text { Non-fuzzy } \\
\widetilde{B}_{i}\end{array}$ & $\widetilde{U}_{i}=\frac{A_{i}}{\widetilde{B_{i}}}$ & $\begin{array}{l}\text { Fuzzy full } \\
\text { multiplicative } \\
\text { ranking }\end{array}$ \\
\hline S1 & 0.4111 & 0.68 & 0.8819 & 0.6587 & 0.8138 & 0.924 & 0.6577 & 0.7988 & 0.8233 & 7 \\
\hline $\mathrm{S} 2$ & 0.5702 & 0.7154 & 0.8199 & 0.5036 & 0.7256 & 0.9685 & 0.7018 & 0.7325 & 0.9581 & 1 \\
\hline $\mathrm{S} 3$ & 0.5004 & 0.6955 & 0.8573 & 0.5102 & 0.767 & 0.9557 & 0.6844 & 0.7443 & 0.9195 & 2 \\
\hline $\mathrm{S} 4$ & 0.422 & 0.6814 & 0.8792 & 0.5786 & 0.7991 & 0.9397 & 0.6609 & 0.7725 & 0.8556 & 6 \\
\hline S5 & 0.3422 & 0.6664 & 0.901 & 0.6636 & 0.8146 & 0.9226 & 0.6365 & 0.8003 & 0.7954 & 8 \\
\hline S6 & 0.3726 & 0.6738 & 0.8881 & 0.7009 & 0.8216 & 0.9096 & 0.6448 & 0.8107 & 0.7954 & 9 \\
\hline S7 & 0.5564 & 0.7134 & 0.8249 & 0.7001 & 0.8233 & 0.9088 & 0.6983 & 0.8107 & 0.8613 & 4 \\
\hline S8 & 0.5489 & 0.7096 & 0.8312 & 0.6878 & 0.8224 & 0.9102 & 0.6966 & 0.8068 & 0.8634 & 3 \\
\hline S9 & 0.3297 & 0.6642 & 0.9028 & 0.7197 & 0.8282 & 0.8992 & 0.6322 & 0.8157 & 0.7751 & 10 \\
\hline S10 & 0.5571 & 0.7157 & 0.8218 & 0.7116 & 0.8283 & 0.9 & 0.6982 & 0.8133 & 0.8585 & 5 \\
\hline S11 & 0.3211 & 0.6399 & 0.913 & 0.7033 & 0.8252 & 0.9037 & 0.6247 & 0.8107 & 0.7705 & 11 \\
\hline $\mathrm{S} 12$ & 0.3055 & 0.6362 & 0.9179 & 0.6943 & 0.8207 & 0.9118 & 0.6199 & 0.8089 & 0.7663 & 12 \\
\hline
\end{tabular}

mainly resorts to Beck and Lin (1983)'s guidelines for consensus ranking. Emond and Mason (2002, p. 17) provide a solution to the consensus ranking problem by coming up with a measure of agreement between pairs of ranking and choosing those rankings which maximize overall average agreement. The $\mathrm{MAH}$ is an effective consensus ranking method used within a wide span of multi-criteria decision-making problems (Kengpol and Tuominen 2006; Tavana 2002, 2003, 2004; Tavana et al. 1996; Tavana and Banerjee 1995).

In this research, the MAH method is applied to arrive at a final ranking of the alternatives (objects) selected by different raters (methods, i.e., fuzzy FM rankings, fuzzy COPRAS, fuzzy RP rankings, and fuzzy ratio method rankings). Given $k$ multi-criteria methods that have all ranked $n$ alternatives, an agreement matrix, $A$, is defined, where $a_{i j}$ indicates the number of methods which prefer alternative $i$ over $j$. If the summation for each alternative $i$ is calculated for all the columns, a column vector in which each element shows the total number of times alternative $i$ is favored over all other alternatives are created. This vector is called the positive preference vector $P$ :

$P_{i}=\sum_{j=1}^{n} a_{i j}, i=1,2,3, \ldots, n$

In addition, if the summation for each alternative $j$ is calculated for all rows, a row vector in which each element shows the total number of times alternative $j$ isn't favored over all other alternatives is created. This vector is called the negative preference vector $N$ :

$N_{i}=\sum_{j=1}^{n} a_{j i}, i=1,2,3, \ldots, n$.

This study uses Eqs. (46) and (47) and formulate the following selection criterion. If alternative $i$ receives a zero-value

Table 17 Alternative rankings with the fuzzy full multiplicative form-HFBWM

\begin{tabular}{|c|c|c|c|c|c|c|c|c|c|c|}
\hline Supplier & $\widetilde{A_{i}}$ & & & $\widetilde{B}_{i}$ & & & Non-fuzzy $\widetilde{A}_{i}$ & Non-fuzzy $\widetilde{B}_{i}$ & $\widetilde{U}_{i}^{\prime}=\frac{A_{i}}{\widetilde{B}_{i}}$ & Fuzzy full multiplicative ranking \\
\hline $\mathrm{S} 1$ & 0.856 & 0.931 & 0.975 & 0.845 & 0.921 & 0.969 & 0.921 & 0.911 & 1.01 & 7 \\
\hline $\mathrm{S} 2$ & 0.897 & 0.938 & 0.964 & 0.765 & 0.872 & 0.988 & 0.933 & 0.875 & 1.066 & 1 \\
\hline $\mathrm{S} 3$ & 0.882 & 0.934 & 0.969 & 0.76 & 0.895 & 0.983 & 0.929 & 0.879 & 1.056 & 2 \\
\hline S4 & 0.861 & 0.931 & 0.973 & 0.806 & 0.914 & 0.976 & 0.922 & 0.899 & 1.026 & 3 \\
\hline S5 & 0.819 & 0.926 & 0.98 & 0.854 & 0.922 & 0.967 & 0.908 & 0.914 & 0.994 & 8 \\
\hline S6 & 0.824 & 0.927 & 0.979 & 0.869 & 0.925 & 0.962 & 0.91 & 0.919 & 0.991 & 9 \\
\hline S7 & 0.889 & 0.936 & 0.966 & 0.86 & 0.923 & 0.965 & 0.931 & 0.916 & 1.016 & 5 \\
\hline S8 & 0.889 & 0.936 & 0.967 & 0.852 & 0.922 & 0.966 & 0.931 & 0.914 & 1.019 & 4 \\
\hline S9 & 0.811 & 0.925 & 0.981 & 0.88 & 0.929 & 0.956 & 0.906 & 0.922 & 0.983 & 10 \\
\hline $\mathrm{S} 10$ & 0.892 & 0.937 & 0.965 & 0.865 & 0.925 & 0.962 & 0.931 & 0.917 & 1.015 & 6 \\
\hline $\mathrm{S} 11$ & 0.793 & 0.914 & 0.985 & 0.863 & 0.924 & 0.963 & 0.897 & 0.917 & 0.979 & 11 \\
\hline $\mathrm{S} 12$ & 0.791 & 0.915 & 0.985 & 0.869 & 0.924 & 0.962 & 0.897 & 0.919 & 0.977 & 12 \\
\hline
\end{tabular}


Table 18 Fuzzy MULTIMOORA rankings (aggregation and comparison)-FShannon

\begin{tabular}{lllll}
\hline Supplier & $\begin{array}{l}\text { Fuzzy ratio method rankings } \\
\text { (Table 12) }\end{array}$ & $\begin{array}{l}\text { Fuzzy reference point rankings } \\
\text { (Table 14) }\end{array}$ & $\begin{array}{l}\text { Fuzzy full multiplicative rankings } \\
\text { (Table 16) }\end{array}$ & $\begin{array}{l}\text { Fuzzy MULTIMOORA } \\
\text { ranking }\end{array}$ \\
\hline S1 & 7 & 4 & 7 & 7 \\
S2 & 1 & 1 & 1 & 1 \\
S3 & 2 & 2 & 2 & 2 \\
S4 & 6 & 3 & 6 & 6 \\
S5 & 9 & 5 & 8 & 8 \\
S6 & 8 & 7 & 9 & 9 \\
S7 & 4 & 8 & 4 & 4 \\
S8 & 3 & 9 & 3 & 3 \\
S9 & 10 & 11 & 10 & 10 \\
S10 & 5 & 10 & 5 & 5 \\
S11 & 11 & 12 & 11 & 11 \\
S12 & 12 & 6 & 12 & 12 \\
\hline
\end{tabular}

entry in the negative preference vector $N$, it indicates that alternative $i$ isn't ranked lower than other alternatives. Therefore, if alternative $i$ is entered in the upcoming obtainable value from the uppermost of FCR, there is no disappointment when the result of the objective function is reached. However, suppose alternative $i$ receives a zero-value entry in the positive preference vector $P$. In that case, this indicates that this alternative isn't ranked ahead of other alternatives, following Beck and Lin's (1983) guidelines. Thus, alternative $i$ has no positive impact on the objective function and should be placed in the lowest available consensus ranking position, according to Beck and Lin (1983). The quantity $\left(P_{i}-N_{i}\right)$ provides a reasonable selection criterion for cases in which there exist no zero entries in each negative and positive preference vectors. Therefore, it seems more logical to consider the max
$\left|P_{i}-N_{i}\right|$. when concentrating on $\max \left|P_{i}-N_{i}\right|$; if $\left(P_{i}-N_{i}\right)$ is positive, alternative $i$ should be put at the top of the FCR because alternative $i$ has the greatest positive impact on the objective function. Similarly, if for the max $\left|P_{i}-N_{i}\right|$, the $\left(P_{i}-\right.$ $N_{i}$ ) gets a negative value, alternative $i$ should be placed at the upcoming obtainable position at the bottom of the ranking because this placement of alternative $i$ reduces that alternative's negative effect on the objective function. The following algorithm formulates the discourse above:

Step 1: In this step, the agreement matrix $A$ is produced, and parameter $n$ is set equal to the number of alternatives.

Step 2: In this step, Eqs. (48) and (49) are used to compute the entries for the negative and positive preference vectors $N$ and $P$ :
Table 19 Fuzzy

MULTIMOORA rankings (aggregation and comparison)HFBWM

\begin{tabular}{lllll}
\hline Supplier & $\begin{array}{l}\text { Fuzzy ratio method } \\
\text { rankings (Table 13) }\end{array}$ & $\begin{array}{l}\text { Fuzzy reference point } \\
\text { rankings (Table 15) }\end{array}$ & $\begin{array}{l}\text { Fuzzy full multiplicative } \\
\text { rankings (Table 17) }\end{array}$ & $\begin{array}{l}\text { Fuzzy } \\
\text { MULTIMOORA } \\
\text { ranking }\end{array}$ \\
\hline S1 & 7 & 7 & 7 & 7 \\
S2 & 1 & 1 & 1 & 1 \\
S3 & 2 & 2 & 2 & 2 \\
S4 & 3 & 3 & 3 & 3 \\
S5 & 8 & 8 & 8 & 8 \\
S6 & 9 & 9 & 10 & 9 \\
S7 & 5 & 5 & 5 & 5 \\
S8 & 4 & 4 & 4 & 4 \\
S9 & 10 & 10 & 12 & 10 \\
S10 & 6 & 6 & 6 & 6 \\
S11 & 11 & 11 & 9 & 11 \\
S12 & 12 & 12 & 11 & 12 \\
\hline
\end{tabular}


Table 20 Fuzzy TOPSIS rankings-FShannon

\begin{tabular}{llll}
\hline Supplier & $d+$ & $d-$ & $\begin{array}{l}\text { Fuzzy full multiplicative } \\
\text { rankings (Table 10) }\end{array}$ \\
\hline S1 & 13.2678 & 0.014 & 7 \\
S2 & 12.7863 & 0.0334 & 1 \\
S3 & 13.0154 & 0.0232 & 5 \\
S4 & 13.2215 & 0.0158 & 6 \\
S5 & 13.3849 & 0.0102 & 9 \\
S6 & 13.3533 & 0.0118 & 8 \\
S7 & 12.9701 & 0.0271 & 2 \\
S8 & 13.0294 & 0.0243 & 4 \\
S9 & 13.4205 & 0.0097 & 10 \\
S10 & 13.0087 & 0.0256 & 3 \\
S11 & 13.4457 & 0.0091 & 11 \\
S12 & 13.4521 & 0.009 & 12 \\
\hline
\end{tabular}

$P_{i}=\sum_{j}^{n} a_{i j}$

$N_{i}=\sum_{j}^{n} a_{j i}$

Step 3: In this step, any alternatives with zero-value entries in each of both negative and positive preference vectors are candidates for entry into the FCR. In line with the guidelines of Beck and Lin (1983), if the zero-value entry takes place in the positive preference vector $P$, this study enters alternative $i$ in the upcoming obtainable value from the lowermost of consensus ranking. However, if the zero-value entry

Table 21 Fuzzy TOPSIS rankings-HFBWM

\begin{tabular}{llll}
\hline Supplier & $d+$ & $d-$ & $\begin{array}{l}\text { Fuzzy full multiplicative } \\
\text { rankings (Table 10) }\end{array}$ \\
\hline S1 & 13.814 & 0.001 & 7 \\
S2 & 13.697 & 0.003 & 1 \\
S3 & 13.735 & 0.003 & 2 \\
S4 & 13.796 & 0.002 & 4 \\
S5 & 13.85 & 0.001 & 8 \\
S6 & 13.857 & 0.001 & 11 \\
S7 & 13.773 & 0.002 & 3 \\
S8 & 13.786 & 0.002 & 6 \\
S9 & 13.863 & 0.001 & 10 \\
S10 & 13.784 & 0.002 & 5 \\
S11 & 13.869 & 0.001 & 12 \\
S12 & 13.866 & 0.001 & 9 \\
\hline
\end{tabular}

takes place in the negative preference vector $N$, current research enters alternative $i$ in the upcoming obtainable value in the uppermost of the ranking. In either case, this research reduces the row and column effects of the alternatives in matrix $A$ and subsequently moves to Step 5 , as shown below.

Step 4: In this step, this study examines the $P_{i}-N_{i}$ difference for all $i$ in case there is no zero-value entries in both $N$ or $P$. Furthermore, alternative $i$ is chosen with the largest absolute difference, and alternative $i$ is entered in the upcoming obtainable value from the uppermost of the ranking in case a positive difference is achieved. In this step, alternative $i$ is entered in the upcoming obtainable value from the lower level of the ranking if the difference is negative, according to Beck and Lin (1983). In case of a tie where more than one alternative is a candidate for the FCR, the tie is broken arbitrarily. In the next step, the row and column results of the agreement matrix $A$ are subsequently removed for alternative $i$ accordingly.

Step 5: In this step, set $n=n-1$

Step 6: In this step, if $n>1$, move to Step 2, and if $n=1$, enter the last alternative in the upcoming obtainable position on the top of the ranking and stop.

Finally, the above exploratory process in this study is applied to solve both incomplete and complete ranking problems. In a complete ranking problem, all methods have ordinally or cardinally ranked every alternative. In contrast, in an incomplete ranking problem, each method ranks only a subset of the alternatives (Beck and Lin 1983).

\section{Case study}

In this section, this research presents a case study in the asphalt manufacturing industry to signify the adequacy and applicability of the suggested model of this study. Technopave ${ }^{1}$ is the largest asphalt manufacturing company in southern Pennsylvania using tire powder recycled by suppliers to produce road-paving asphalt. The tire powder is the main asphalt ingredient with several advantages, including increasing strength and stability, decreasing thickness, increasing life span, reducing maintenance costs, improving bitumen adhesion, reducing crack, and having more resistant to high temperatures. In summary, using tire powder in asphalt creates rubberized asphalt, which has much better quality than ordinary asphalt. Technopave is considering twelve alternative suppliers with tire recycling capabilities for their rubberized asphalt line. This research used the model proposed in this study to help Technopave choose the most preferred suppliers.

\footnotetext{
${ }^{1}$ The name of the company is changed to protect its anonymity.
} 
Table 22 The initial individual rankings-FShannon

\begin{tabular}{lllllllllllll}
\hline Method & \multicolumn{1}{l}{ Supplier } & & 1 & & & & & & & & \\
\cline { 2 - 10 } & S1 & S2 & S3 & S4 & S5 & S6 & S7 & S8 & S9 & S10 & S11 & S12 \\
\hline $\begin{array}{c}\text { Fuzzy COPRAS ranking } \\
\quad \text { Table 10) }\end{array}$ & 7 & 1 & 2 & 3 & 8 & 9 & 5 & 4 & 10 & 6 & 11 & 12 \\
$\begin{array}{c}\text { Fuzzy MULTIMOORA } \\
\text { ranking (Table 18) }\end{array}$ & 7 & 1 & 2 & 6 & 8 & 9 & 4 & 3 & 10 & 5 & 11 & 12 \\
$\begin{array}{c}\text { Fuzzy TOPSIS ranking } \\
\quad \text { Table 20) }\end{array}$ & 7 & 1 & 5 & 6 & 9 & 8 & 2 & 4 & 10 & 3 & 11 & 12 \\
\hline
\end{tabular}

\section{Fuzzy Shannon results}

Technopave appointed six managers to this project. This study used their expert opinions to compute the weight of the green supplier assessment benchmarks, according to Eqs. (1) to (5) and the linguistic variables presented in Table 4. As tabulated in Table 4, this study used Eq. (1) to normalize the interval DM. In addition, this research used Eq. (2) to calculate the lower and upper limits, respectively. Next, Eq. (3) is utilized to assign the base and upper value limits of the diversification intervals. In the next step, this study used Eqs. (4) and (5) to compute the weights of the benchmark presented in Table 5 . These benchmarks weights were applied in this research for the fuzzy COPRAS, fuzzy MULTIMOORA, and fuzzy TOPSIS methods for the sake of ranking the suppliers.

\section{HFBWM results}

In this section, the weights of the criteria and sub-criteria are calculated using HFBWM. We asked several experts to identify the best and worst criteria and sub-criteria to determine the fuzzy preference of the best criterion relative to the other criteria and that of all criteria relative to the worst criterion on a scale from 1 to 5 . The same procedure was applied to the different sub-criteria.

The resulting fuzzy preferences are presented in Tables 6 and 7. The model proposed in Eq. (10) is then applied to calculate the weights of the criteria and sub-criteria, as well as the global weights of the sub-criteria. These latter weights, described in Table 8, will be implemented within the fuzzy COPRAS, fuzzy MULTIMOORA, and fuzzy TOPSIS methods to rank the suppliers.

The consistency of the model is calculated using Eq. (12), with $\xi^{*}$ determined by running the model in LINGO 18 software. The optimal $\xi^{*}$ equals 0.56155 , with $\mathrm{CI}=6.69$ (as described in Table 2) and CR $=0.0839$. The CR is close to 0 , implying that our model has high consistency.

\section{Fuzzy COPRAS results}

After determining the green supply chain criteria weights based on expert opinions, we used the fuzzy Shannon entropy approach, HFBWM, and the fuzzy COPRAS to rank the suppliers according to Eqs. (13) to (23). This study first used Eq. (13) to assess the FDM for every supplier (see Table 9). Equations (14) to (16) are then applied to normalize the FDM. Next, the fuzzy Shannon entropy weights presented in Table 5 and the HFBWM weights presented in Table 8 are utilized to calculate the weighted normalized FDM for each supplier.

In the final step, Eqs. (17) to 23) and the fuzzy COPRAS method are applied to rank the suppliers utilizing the weighted normalized FDM tabulated. Equtations (17) and (18) were used to estimate the total of the aggregate values of the parameters for the maximum and minimum values, respectively. Next, Eq. (20) is used to calculate the comparative importance of every option, and Eq. (21) is computed to defuzzify them. To rank the suppliers, as the next step, Eqs. (20) and (23) are applied

Table 23 The initial individual rankings-HFBWM

\begin{tabular}{|c|c|c|c|c|c|c|c|c|c|c|c|c|}
\hline \multirow[t]{2}{*}{ Method } & \multicolumn{12}{|c|}{ Supplier } \\
\hline & $\mathrm{S} 1$ & $\mathrm{~S} 2$ & S3 & S4 & S5 & S6 & S7 & $\mathrm{S} 8$ & S9 & S10 & $\mathrm{S} 11$ & $\mathrm{~S} 12$ \\
\hline Fuzzy COPRAS ranking (Table 11) & 7 & 1 & 2 & 3 & 8 & 9 & 5 & 4 & 10 & 6 & 11 & 12 \\
\hline Fuzzy ratio method rankings (Table 13) & 7 & 1 & 2 & 3 & 8 & 9 & 5 & 4 & 10 & 6 & 11 & 12 \\
\hline Fuzzy reference point rankings (Table 15) & 7 & 1 & 2 & 3 & 8 & 10 & 5 & 4 & 12 & 6 & 9 & 11 \\
\hline Fuzzy full multiplicative rankings (Table 17) & 7 & 1 & 2 & 3 & 8 & 9 & 5 & 4 & 10 & 6 & 11 & 12 \\
\hline Fuzzy TOPSIS ranking (Table 21) & 7 & 1 & 2 & 4 & 8 & 11 & 3 & 6 & 10 & 5 & 12 & 9 \\
\hline
\end{tabular}


Table 24 Consensus ranking calculations using MAH-FShannon

\begin{tabular}{llllllllllllllll}
\hline Supplier & $\mathrm{S} 1$ & $\mathrm{~S} 2$ & $\mathrm{~S} 3$ & $\mathrm{~S} 4$ & $\mathrm{~S} 5$ & $\mathrm{~S} 6$ & $\mathrm{~S} 7$ & $\mathrm{~S} 8$ & $\mathrm{~S} 9$ & $\mathrm{~S} 10$ & $\mathrm{~S} 11$ & $\mathrm{~S} 12$ & $P_{i}$ & $P_{i}-N_{i}$ & $R a n k\left(P_{i}-N_{i}\right)$ \\
\hline S1 & 0 & 0 & 0 & 0 & 3 & 3 & 0 & 0 & 3 & 0 & 3 & 3 & 15 & -3 & 7 \\
S2 & 3 & 0 & 3 & 3 & 3 & 3 & 3 & 3 & 3 & 3 & 3 & 3 & 33 & 33 & 1 \\
S3 & 3 & 0 & 0 & 3 & 3 & 3 & 2 & 2 & 3 & 2 & 3 & 3 & 27 & 21 & 2 \\
S4 & 3 & 0 & 0 & 0 & 3 & 3 & 1 & 1 & 3 & 1 & 3 & 3 & 21 & 9 & 6 \\
S5 & 0 & 0 & 0 & 0 & 0 & 2 & 0 & 3 & 3 & 0 & 3 & 3 & 14 & -5 & 8 \\
S6 & 0 & 0 & 0 & 0 & 1 & 0 & 0 & 0 & 3 & 0 & 3 & 3 & 10 & -13 & 9 \\
S7 & 3 & 0 & 1 & 2 & 3 & 3 & 0 & 1 & 3 & 3 & 3 & 3 & 25 & -7 & 3 \\
S8 & 3 & 0 & 1 & 2 & 0 & 3 & 2 & 0 & 3 & 2 & 3 & 3 & 22 & 11 & 4 \\
S9 & 0 & 0 & 0 & 0 & 0 & 0 & 0 & 0 & 0 & 0 & 3 & 3 & 6 & -21 & 10 \\
S10 & 3 & 0 & 1 & 2 & 3 & 3 & 0 & 1 & 3 & 0 & 3 & 3 & 22 & 11 \\
S11 & 0 & 0 & 0 & 0 & 0 & 0 & 0 & 0 & 0 & 0 & 0 & 3 & 3 & -27 & 11 \\
S12 & 0 & 0 & 0 & 0 & 0 & 0 & 0 & 0 & 0 & 0 & 0 & 0 & 0 & -33 & 12 \\
$N_{i}$ & 18 & 0 & 6 & 12 & 19 & 23 & 8 & 11 & 27 & 11 & 30 & 33 & &
\end{tabular}

accordingly. The supplier rankings are tabulated in Tables 10 and 11. The findings of these tables, resulting from the fuzzy Shannon entropy and HFBWM-FCOPRAS approaches, suggest that supplier 2 is the most preferred provider.

\section{Fuzzy MULTIMOORA}

This study applies the fuzzy MULTIMOORA approach in assessing the alternatives. Twelve different suppliers (S1, $\mathrm{S} 2, \mathrm{~S} 3, \ldots, \mathrm{S} 11$, and $\mathrm{S} 12$ ) were considered in the evaluation process. This research applied Eqs. (23), (24), and (25) to normalize the FDM. In addition, Eqs. (26), (27), and (28) are applied for the sake of computing the weighted normalized FDMs for the benefits and cost. Equation (29) is used to compute the total ratings of the benchmarks of the alternative. Furthermore, Eqs. (30), (31), and (32) are used for the benefit benchmarks to calculate the alternatives' total ratings for the lower-middle-upper measures of the triangular membership formula. In addition, considering the cost measures, Eqs. (33), (34), and (35) are applied to calculate the total score of an alternative for the lower-middle-upper values of the triangular membership formula, respectively. Further, Eq. (36) is used to defuzzify the overall score of the measures. By virtue of the fuzzy ratio system approach, the results of the ranking for suppliers are tabulated in Tables 12 and 13. Based on both approaches, namely, fuzzy Shannon entropy and HFBWM, supplier 2 is shown as the distinguished alternative provider for the Technopave company.

Next, utilizing the fuzzy RP method, Eqs. (37) and (38) are used to compute the overall performance measure of the alternatives (Adalı and Işık 2017). Equation (36) is then applied to compute the fuzzy RPs rankings presented in Tables 14 and

Table 25 Consensus ranking calculations using MAH-HFBWM

\begin{tabular}{llllllllllllllll}
\hline Supplier & $\mathrm{S} 1$ & $\mathrm{~S} 2$ & $\mathrm{~S} 3$ & $\mathrm{~S} 4$ & $\mathrm{~S} 5$ & $\mathrm{~S} 6$ & $\mathrm{~S} 7$ & $\mathrm{~S} 8$ & $\mathrm{~S} 9$ & $\mathrm{~S} 10$ & $\mathrm{~S} 11$ & $\mathrm{~S} 12$ & $P_{i}$ & $P_{i}-N_{i}$ & $R a n k\left(P_{i}-N_{i}\right)$ \\
\hline $\mathrm{S} 1$ & 0 & 0 & 0 & 0 & 5 & 5 & 0 & 0 & 5 & 0 & 5 & 5 & 25 & -5 & 7 \\
$\mathrm{~S} 2$ & 5 & 0 & 5 & 5 & 5 & 5 & 5 & 5 & 5 & 5 & 5 & 5 & 55 & 55 & 1 \\
$\mathrm{~S} 3$ & 5 & 0 & 0 & 5 & 5 & 5 & 5 & 5 & 5 & 5 & 5 & 5 & 50 & 45 & 2 \\
S4 & 5 & 0 & 0 & 0 & 5 & 5 & 4 & 5 & 5 & 5 & 5 & 5 & 44 & 33 & 3 \\
S5 & 0 & 0 & 0 & 0 & 0 & 5 & 0 & 0 & 5 & 0 & 5 & 5 & 20 & -15 & 8 \\
S6 & 0 & 0 & 0 & 0 & 0 & 0 & 0 & 0 & 4 & 0 & 4 & 4 & 12 & -31 & 9 \\
S7 & 5 & 0 & 0 & 1 & 5 & 5 & 0 & 1 & 5 & 5 & 5 & 5 & 37 & 19 & 5 \\
S8 & 5 & 0 & 0 & 0 & 5 & 5 & 4 & 0 & 5 & 4 & 5 & 5 & 38 & 21 \\
S9 & 0 & 0 & 0 & 0 & 0 & 1 & 0 & 0 & 0 & 0 & 4 & 3 & 8 & -39 & 10 \\
S10 & 5 & 0 & 0 & 0 & 5 & 5 & 0 & 1 & 5 & 0 & 5 & 5 & 31 & 7 \\
S11 & 0 & 0 & 0 & 0 & 0 & 1 & 0 & 0 & 1 & 0 & 0 & 4 & 6 & -43 & 11 \\
S12 & 0 & 0 & 0 & 0 & 0 & 1 & 0 & 0 & 2 & 0 & 1 & 0 & 4 & -47 & 12 \\
$N_{i}$ & 30 & 0 & 5 & 11 & 35 & 43 & 18 & 17 & 47 & 24 & 49 & 51 & &
\end{tabular}




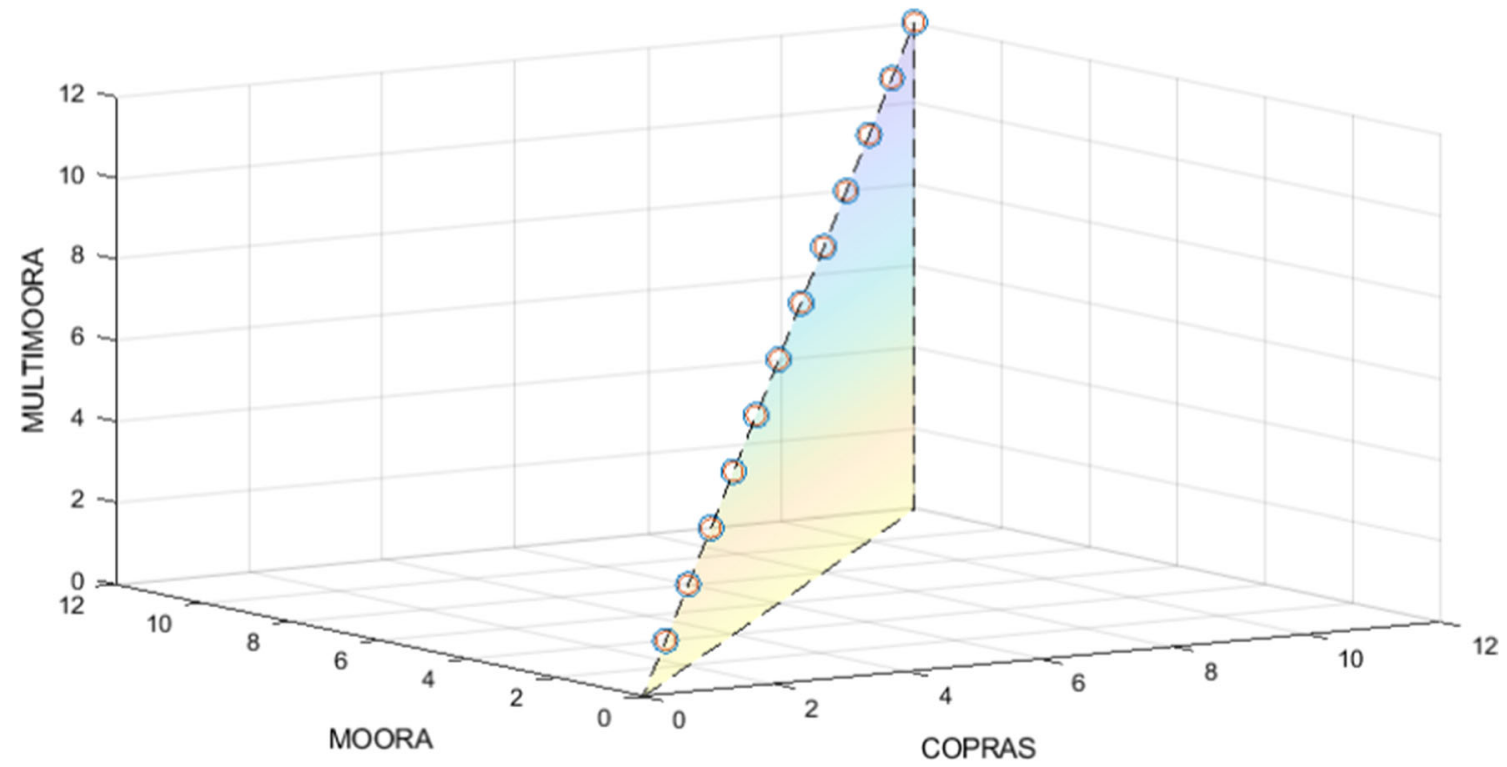

(a)

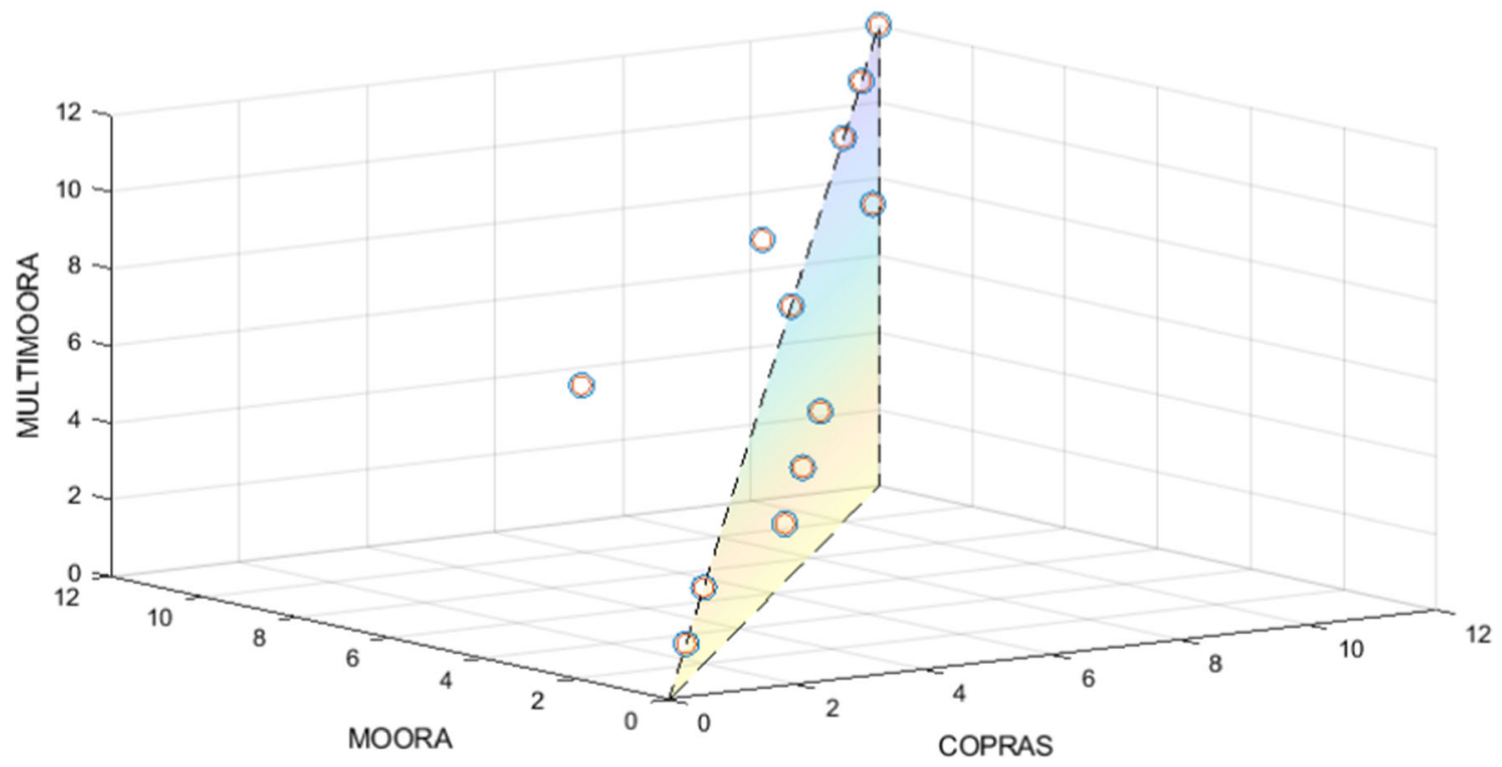

(b)

Fig. 4 Rank similarity among COPRAS, MOORA, and MULTIMOORA. a HFBWM framework. b Fuzzy Shannon entropy framework

15. Based on the fuzzy RP approach, together with fuzzy Shannon entropy and HFBWM, supplier 2 is the distinguished alternative provider for the Technopave company.

In addition, the FMF of multi-criteria is computed using Eq. (39). The FMF is non-additive and non-linear, and the form doesn't utilize the weights of the measures. The overall utility functions of the alternatives utilizing the $\operatorname{FMF}\left(\widetilde{U}_{i}^{\prime}\right)$ are tabulated in Table 16. Considering the fact that the overall utility function has a fuzzy digit, defuzzification is required based on Eq. (36) for the sake of computing $B N P_{i}$ values and grade each of the alternatives. Table 16 highlights the overall ranking for the suppliers. Based on the FMF approach, combined with fuzzy Shannon entropy and HFBWM, supplier 2 is the most distinguished alternative for the Technopave company.

In addition, being rooted in dominance theory, the final rankings presented in Tables 18 and 19 are computed for all the suppliers utilizing the fuzzy MULTIMOORA, together with fuzzy Shannon entropy and HFBWM. The results show that supplier 2 is the most preferred supplier. 


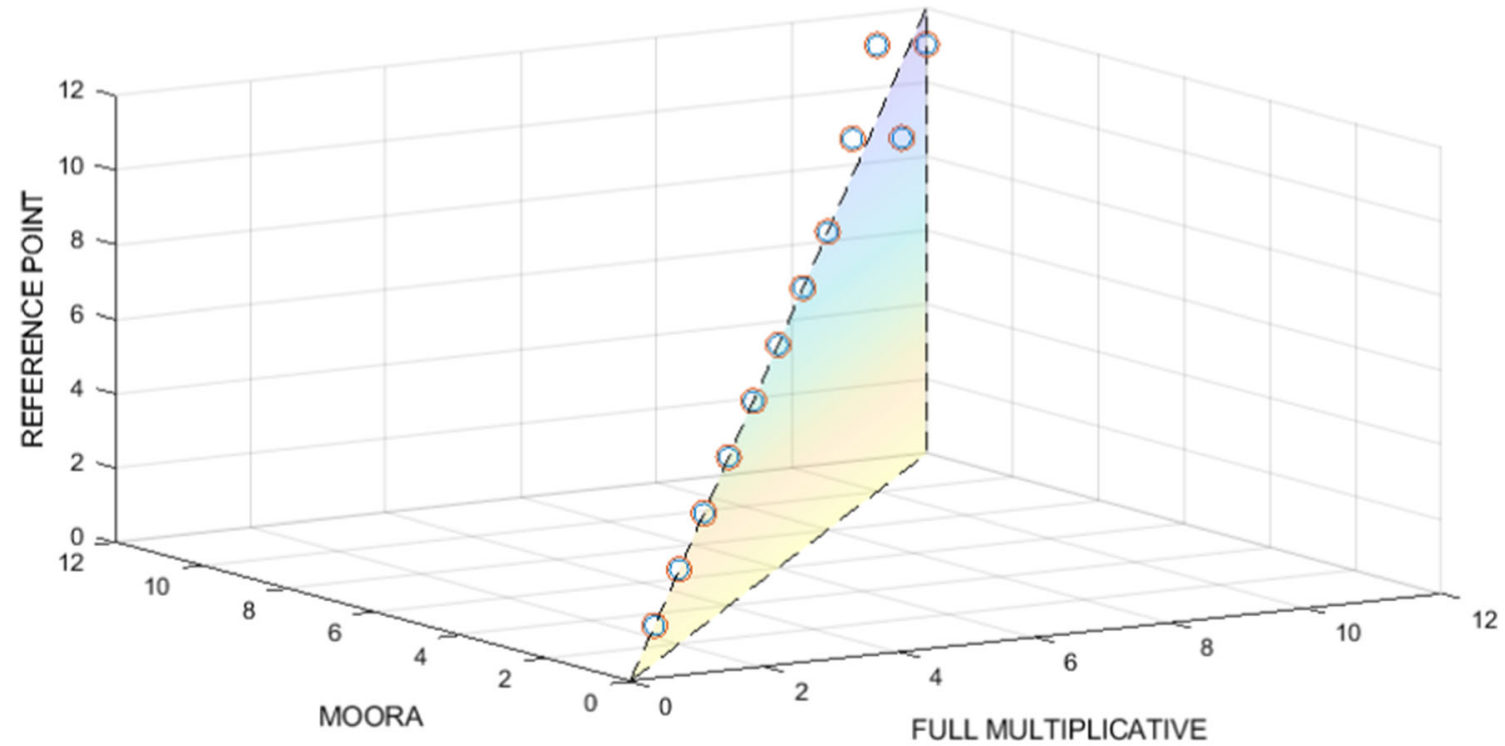

(a)

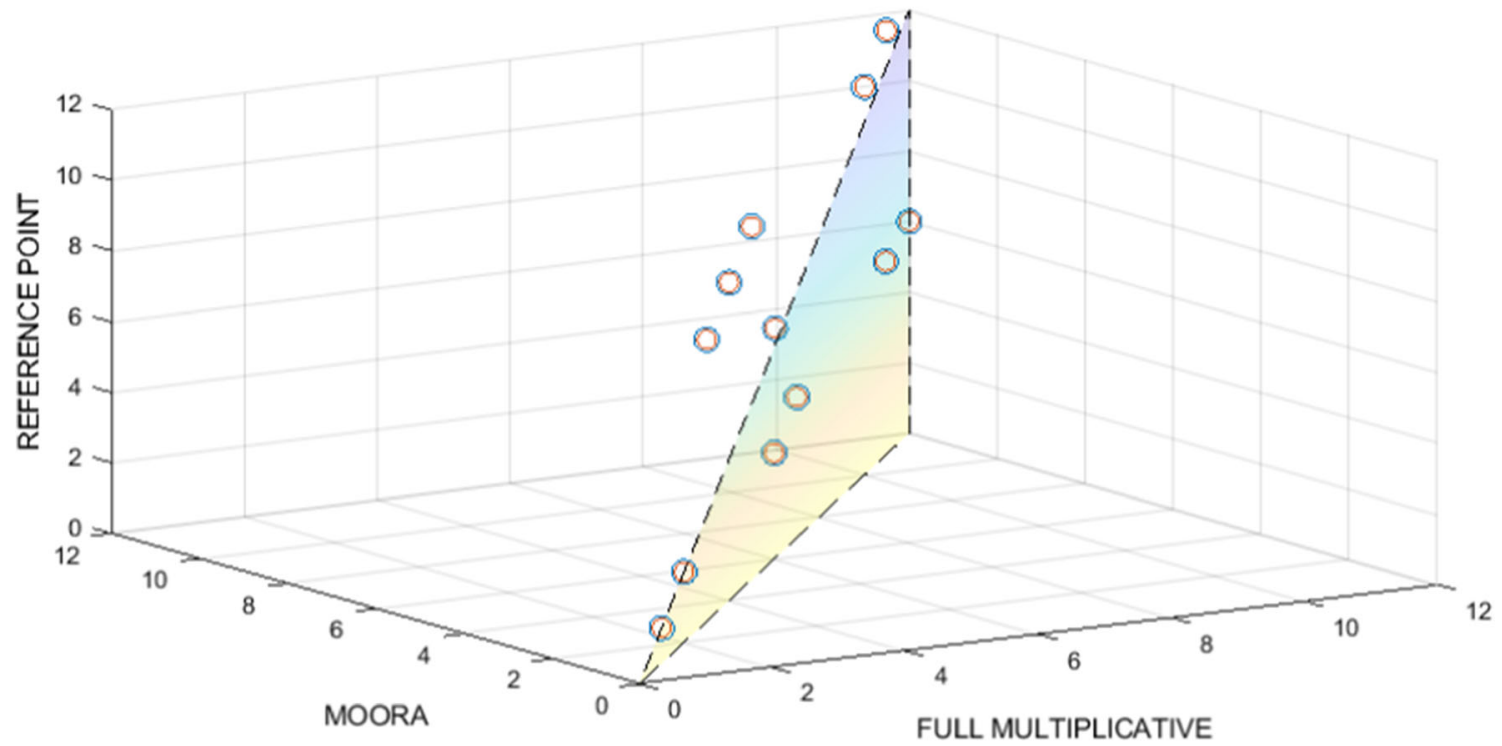

(b)

Fig. 5 Rank similarity among full multiplicative, MOORA, and reference point. a. HFBWM framework. b Fuzzy Shannon entropy framework

\section{Fuzzy TOPSIS results}

For comparative purposes, the fuzzy TOPSIS method is applied to assess the alternatives. Twelve different suppliers (S1, $\mathrm{S} 2, \mathrm{~S} 3, \ldots, \mathrm{S} 11$, and S12) were considered in the evaluation process, which applies the results described in Table 9 together with Eqs. (43) to (45) to generate a ranking. Based on the fuzzy TOPSIS approach, combined with fuzzy Shannon entropy and HFBWM, supplier 2 is the most preferred one. The corresponding results are presented in Tables 20 and 21 .

As illustrated in these tables, the ranking results delivered by FTOPSIS differ from those of FCOPRAS and FMULTIMOORA. These latter techniques focus on the maximum and minimum values of the attributes, as described within Eqs. (17), (18), and (20) and Eqs. (31), (40) and (41), respectively, to generate the corresponding rankings. On the other hand, FTOPSIS is based on comparisons relative to the positive and negative ideal solution benchmarks, increasing its susceptibility to the weights assigned to the criteria. As a result, the rankings delivered by these techniques are expected to differ whenever the weighting methods differ.

\section{Consensus raking}

Given the different results obtained, we use the MAH to reach a consensus raking of the alternative rankings proposed by 
Table 26 Correlations among the different rankings under FShannon

COPRAS MOORA MULTIMOORA Reference point Full multiplicative TOPSIS

\begin{tabular}{|c|c|c|c|c|c|c|c|c|}
\hline \multirow[t]{18}{*}{ Spearman's rho } & COPRAS & Correlation coefficient & 1.000 & $0.951 * *$ & $0.958 * *$ & $0.622 *$ & $0.958 * *$ & $0.867 * *$ \\
\hline & & Sig. (2-tailed) & & 0.000 & 0.000 & 0.031 & 0.000 & 0.000 \\
\hline & & $N$ & 12 & 12 & 12 & 12 & 12 & 12 \\
\hline & MOORA & Correlation coefficient & $0.951 * *$ & 1.000 & $0.993 * *$ & 0.483 & $0.993 * *$ & $0.937 * *$ \\
\hline & & Sig. (2-tailed) & 0.000 & & 0.000 & 0.112 & 0.000 & 0.000 \\
\hline & & $N$ & 12 & 12 & 12 & 12 & 12 & 12 \\
\hline & MULTIMOORA & Correlation coefficient & $0.958 * *$ & $0.993 * *$ & 1.000 & 0.497 & $1.000 * *$ & $0.930 * *$ \\
\hline & & Sig. (2-tailed) & 0.000 & 0.000 & & 0.101 & & 0.000 \\
\hline & & $N$ & 12 & 12 & 12 & 12 & 12 & 12 \\
\hline & Reference point & Correlation coefficient & $0.622 *$ & 0.483 & 0.497 & 1.000 & 0.497 & 0.315 \\
\hline & & Sig. (2-tailed) & 0.031 & 0.112 & 0.101 & & 0.101 & 0.319 \\
\hline & & $N$ & 12 & 12 & 12 & 12 & 12 & 12 \\
\hline & Full multiplicative & Correlation coefficient & $0.958 * *$ & $0.993 * *$ & $1.000 * *$ & 0.497 & 1.000 & $0.930 * *$ \\
\hline & & Sig. (2-tailed) & 0.000 & 0.000 & & 0.101 & & 0.000 \\
\hline & & $N$ & 12 & 12 & 12 & 12 & 12 & 12 \\
\hline & TOPSIS & Correlation coefficient & $0.867 * *$ & $0.937 * *$ & $0.930 * *$ & 0.315 & $0.930 * *$ & 1.000 \\
\hline & & Sig. (2-tailed) & 0.000 & 0.000 & 0.000 & 0.319 & 0.000 & \\
\hline & & $N$ & 12 & 12 & 12 & 12 & 12 & 12 \\
\hline
\end{tabular}

**Correlation is significant at the 0.01 level (2-tailed).

*Correlation is significant at the 0.05 level (2-tailed)

fuzzy MULTIMOORA, fuzzy COPRAS, and fuzzy TOPSIS. The MAH evaluates alternatives simultaneously and builds agreement matrices until all alternatives are ranked without any prior ranked alternatives (Tavana et al. 2007). The

Table 27 Correlations among the different rankings under HFBWM

\begin{tabular}{|c|c|c|c|c|c|c|c|c|}
\hline & & & COPRAS & MOORA & MULTIMOORA & Reference point & Full multiplicative & TOPSIS \\
\hline \multirow[t]{18}{*}{ Spearman's rho } & COPRAS & Correlation coefficient & 1.000 & $1.000^{* *}$ & $1.000 * *$ & $0.965^{* *}$ & $1.000 * *$ & $0.916^{* *}$ \\
\hline & & Sig. (2-tailed) & & & & 0.000 & & 0.000 \\
\hline & & $N$ & 12 & 12 & 12 & 12 & 12 & 12 \\
\hline & MOORA & Correlation coefficient & $1.000 * *$ & 1.000 & $1.000 * *$ & $0.965 * *$ & $1.000 * *$ & $0.916^{* *}$ \\
\hline & & Sig. (2-tailed) & & & & 0.000 & & 0.000 \\
\hline & & $N$ & 12 & 12 & 12 & 12 & 12 & 12 \\
\hline & MULTIMOORA & Correlation coefficient & $1.000 * *$ & $1.000 * *$ & 1.000 & $0.965 * *$ & $1.000 * *$ & $0.916 * *$ \\
\hline & & Sig. (2-tailed) & & & & 0.000 & & 0.000 \\
\hline & & $N$ & 12 & 12 & 12 & 12 & 12 & 12 \\
\hline & Reference point & Correlation coefficient & $0.965^{* *}$ & $0.965 * *$ & $0.965 * *$ & 1.000 & $0.965 * *$ & $0.902 * *$ \\
\hline & & Sig. (2-tailed) & 0.000 & 0.000 & 0.000 & & 0.000 & 0.000 \\
\hline & & $N$ & 12 & 12 & 12 & 12 & 12 & 12 \\
\hline & Full multiplicative & Correlation coefficient & $1.000 * *$ & $1.000 * *$ & $1.000 * *$ & $0.965 * *$ & 1.000 & $0.916^{* *}$ \\
\hline & & Sig. (2-tailed) & & & & 0.000 & & 0.000 \\
\hline & & $N$ & 12 & 12 & 12 & 12 & 12 & 12 \\
\hline & TOPSIS & Correlation coefficient & $0.916^{* *}$ & $0.916^{* *}$ & $0.916^{* *}$ & $0.902 * *$ & $0.916 * *$ & 1.000 \\
\hline & & Sig. (2-tailed) & 0.000 & 0.000 & 0.000 & 0.000 & 0.000 & \\
\hline & & $N$ & 12 & 12 & 12 & 12 & 12 & 12 \\
\hline
\end{tabular}

**Correlation is significant at the 0.01 level (2-tailed).

*Correlation is significant at the 0.05 level (2-tailed) 
MAH is conducted by constructing first the matrices given in Tables 22 and 23 to evaluate and compare all alternatives to each other through the ranking results suggested by the methods described in Tables 10-21. That is, Tables 22 and 23 summarize the rankings delivered by each technique.

Next, based on the MAH method, the number of preferences in each row is aggregated to obtain the total number of methods agreeing on each supplier $\left(P_{i}\right)$.. The same procedure is applied to obtain the total number of methods disagreeing on each supplier $\left(N_{i}\right)$.. In case any entry in the $P$ column receives zero-value, the supplier with that entry is included at the top of the FCR. The opposite takes place (the supplier with that entry is included at the bottom of the FCR) in case any entry in the $N$ row receives a zero-value. Then, the greatest positive difference (33 when considering the fuzzy Shannon entropy setting and 55 in the HFBWM case) placed supplier 2 at the top of the final consensus ranking. Following this placement, supplier 2 was deleted, and a new matrix was produced. As tabulated in the next matrix, $\left(P_{i}\right),\left(N_{i}\right)$, and $\left(P_{i}-\right.$ $N_{i}$ ) are calculated for the remaining suppliers. The same procedure is applied to the remaining suppliers. Tables 24 and 25 outline the outcome of the MAH process and indicate the number of times each supplier is favored over the rest by each method, resulting in the final consensus ranking.

We conclude by highlighting an important argument developed throughout the manuscript. Figure 4 illustrates the substantial similarity exhibited by the rankings generated through the fuzzy versions of COPRAS, MOORA, and MULTIMOORA when implementing the HFBWM weights. This similarity contrasts with the lower one exhibited by these ranking techniques when implementing Shannon's entropy's fuzzy extension. A similar intuition follows from the analysis of the rankings delivered by the methods implemented to extend fuzzy MOORA into fuzzy MULTIMOORA, particularly the reference point one. The dissimilarities arising among the corresponding rankings under both weighting techniques are presented in Fig. 5.

Thus, when implementing the HFBWM weights, fuzzy COPRAS suffices to generate rankings that display an identical order to fuzzy MULTIMOORA, a method requiring more elaborated and complex computations. Note also that the fuzzy MOORA and fuzzy MULTIMOORA techniques deliver identical rankings, that is, the procedure required to extend MOORA into MULTIMOORA is not always necessarily justified.

However, this is not the case when implementing the weights generated via fuzzy Shannon's entropy. In this regard, notice how, particularly in the TOPSIS and reference point cases, the rankings obtained display higher variability than those generated using the HFBWM weights. These results are formally complemented through the Spearman rho correlation tests presented in Tables 26 and 27, highlighting that intuitively simpler techniques such as HFBWM can be implemented in more complex evaluation structures while preserving (indeed, improving) the consistency of the rankings obtained.

\section{Discussion}

$\mathrm{RL}$ is one of the key factors determining the success of SC sustainability (Wang et al. 2021a, b, c, d). On the one hand, the worldwide existence of environmental pollution has increased the pressure on companies to consider sustainability in RL (Richnák and Gubová 2021). On the other hand, environmental protection has become a global issue (Daniels 2017), and concerns about environmental protection have stimulated researchers and practitioners to pay more attention to waste recycling. For instance, Yang et al. (2018a, b) investigated waste disposal and management to reduce poverty and pollution in low- and middle-income countries. Li et al. (2020) studied effective policy tools to recycle the waste of construction and demolition. Liu et al. (2020) considered the effect of construction and demolition waste and its recycling when minimizing waste and protecting natural resources. Wang et al. (2020) examined sustainable waste management for household solid waste to raise public awareness.

Even though these studies are informative, additional research is required focusing on each particular industry dealing with RL. Tire waste increases daily due to the increasing population and subsequent demand for tires, which are hazardous to the environment and public health due to the fact that tire waste is not biodegradable and is usually stored and disposed of improperly (Svoboda et al. 2018). The best way to protect the environment and prevent the improper burial of worn-out tires is recycling and the reuse of tire waste. One of the most important applications of tire recycling is its use in the production of asphalt. Several industries, including the asphalt manufacturing industry, have adopted green supply chain philosophy and used recycled tires to produce various products such as rubberized asphalt, rubberized bitumen, reclaim rubber, and rubber ground flooring. Suppliers play an important role in tire recycling as they mainly produce and deliver the tire powder and granule to produce rubberized asphalt. Therefore, finding the best supplier is critical for environmentally conscious.

Research on RL is in its infancy in developing countries, and there is a need for examining green RL initiatives in emerging economies (Bouzon et al. 2016). Companies can embark on RL initiatives by taking small steps and engaging in simple implementation strategies (Hammes et al. 2020). Recycling and green supply chain management are effective strategies for protecting the environment and reducing production costs (Zarbakhshnia et al. 2018). Choosing the right green supplier is a critical success factor in RL systems, and any initiative aimed at reducing production waste in the tire 
industry is beneficial to both the environment and manufacturing companies.

\section{Conclusion, limitations, and future research}

This study proposed a fuzzy green supplier selection model for sustainable supply chains in RL. The HFBWM was applied to determine the importance weights of the green criteria and sub-criteria. For comparative purposes, fuzzy Shannon's entropy was also used to determine the weights of criteria. The fuzzy Shannon's entropy approach and HFBWM were then integrated with fuzzy COPRAS, fuzzy MULTIMOORA, and fuzzy TOPSIS to prioritize and rank suppliers with a robust ability to recycle in RL.

Finally, this research used the MAH method to find the consensus ranking of the suppliers. A real-world case study in the asphalt manufacturing industry was presented to highlight the efficacy and show the applicability of the models suggested in this study. The results derived from the different hybrid models illustrate the higher ranking variability generated by the fuzzy Shannon's entropy weighting method relative to HFBWM.

The main findings of the current paper are of substantial importance for manufacturing companies moving towards a closed-loop supply chain. Future research can extend the methods proposed in this study to industries other than tire recycling ones. Additional research is needed to integrate other relevant methods and expand the number of measures considered to strengthen the precision and accuracy of the proposed assessment and selection model.

We conclude by emphasizing that relatively simple ranking methods such as fuzzy COPRAS and fuzzy MOORA manage to provide sufficiently robust evaluations. In this regard, even though having a larger number of methods at their disposal may seem to endow managers with a complete picture of the evaluation procedure, the use of multiple techniques can also be confusing, particularly when dealing with complex ranking methods implemented through several technical steps.

Acknowledgements Dr. Madjid Tavana is grateful for the partial financial support he received from the Czech Science Foundation (GAČR 1913946S).

Author contributions Madjid Tavana: Conceptualization, formal analysis, methodology, writing — review and editing,and visualization. Akram Shaabani: Investigation, formal analysis, validation and data curation, and software. Francisco Javier Santos-Arteaga: Formal analysis, resources, and visualization. Naser Valaei: Investigation, resources, software, and project administration.

Funding Dr. Madjid Tavana is grateful for the partial support he received from the Czech Science Foundation (GA $\left.{ }^{\circ} \mathrm{CR} 19-13946 \mathrm{~S}\right)$ for this research.
Availability of data and materials Not applicable.

\section{Declarations}

Ethics approval Not applicable.

Consent to participate Not applicable.

Consent for publication Not applicable.

Competing interests The authors declare no competing interests.

\section{References}

Abdel-Basset M, Chang V, Gamal A (2019) Evaluation of the green supply chain management practices: a novel neutrosophic approach. Comput Ind 108:210-220

Abdel-Basset M, Mohamed R (2020) A novel plithogenic TOPSISCRITIC model for sustainable supply chain risk management. J Clean Prod 247:119586. https://doi.org/10.1016/j.jclepro.2019. 119586

Abdullah L, Chan W, Afshari A (2018) Application of PROMETHEE method for green supplier selection: a comparative result based on preference functions. J Industr Eng Int 15:271-285. https://doi.org/ 10.1007/s40092-018-0289-z

Adalı EA, Ișık AT (2017) The multi-objective decision making methods based on MULTIMOORA and MOOSRA for the laptop selection problem. J Industr Eng Int 13(2):229-237

Adhikari B (2000) Reclamation and recycling of waste rubber. Prog Polym Sci 25(7):909-948. https://doi.org/10.1016/S0079-6700(00) 00020-4

Agrawal S, Singh RK, Murtaza Q (2016a) Outsourcing decisions in reverse logistics: sustainable balanced scorecard and graph theoretic approach. Resour Conserv Recycl 108:41-53. https://doi.org/10. 1016/j.resconrec.2016.01.004

Agrawal S, Singh RK, Murtaza Q (2016b) Disposition decisions in reverse logistics by using AHP-fuzzy TOPSIS approach. J Model Manag 11(4):932-948. https://doi.org/10.1108/JM2-12-2014-0091

Akkaya G, Turanoğlu B, Öztaș S (2015) An integrated fuzzy AHP and fuzzy MOORA approach to the problem of industrial engineering sector choosing. Expert Syst Appl 42(24):9565-9573

Alkahtani M, Ziout A, Salah B, Alatefi M, Abd Elgawad AEE, Badwelan A, Syarif U (2021) An insight into reverse logistics with a focus on collection systems. Sustainability 13(2):548. https://doi.org/10. 3390/su13020548

Al-Sharhan S, Karray F, Gueaieb W, Basir O (2001) Fuzzy entropy: a brief survey. In 10th IEEE International Conference on Fuzzy Systems.(Cat. No. 01CH37297) IEEE 3:1135-1139

Amiri M, Hashemi-Tabatabaei M, Ghahremanloo M, KeshavarzGhorabaee M, Zavadskas EK, Antucheviciene J (2020) A new fuzzy approach based on BWM and fuzzy preference programming for hospital performance evaluation: a case study. Appl Soft Comput 92:106279. https://doi.org/10.1016/j.asoc.2020.106279

Amiri MP (2010) Project selection for oil-fields development by using the AHP and fuzzy TOPSIS methods. Expert Syst Appl 37(9):62186224. https://doi.org/10.1016/j.eswa.2010.02.103

Asante D, He Z, Adjei NO, Asante B (2020) Exploring the barriers to renewable energy adoption utilising MULTIMOORA-EDAS method. Energy Policy 142:111479. https://doi.org/10.1016/j.enpol. 2020.111479 
Awasthi A, Baležentis T (2017) A hybrid approach based on BOCR and fuzzy MULTIMOORA for logistics service provider selection. Int J Logist Syst Manag 27(3):261-282

Bai C, Kusi-Sarpong S, Badri Ahmadi H, Sarkis J (2019) Social sustainable supplier evaluation and selection: a group decision-support approach. Int J Prod Res 57(22):7046-7067. https://doi.org/10.1080/ 00207543.2019 .1574042

Bai C, Sarkis J (2010) Integrating sustainability into supplier selection with grey system and rough set methodologies. Int J Prod Econ 124(1):252-264

Bakioglu G, Atahan AO (2021) AHP integrated TOPSIS and VIKOR methods with Pythagorean fuzzy sets to prioritize risks in selfdriving vehicles. Appl Soft Comput 99:106948. https://doi.org/10. 1016/j.asoc.2020.106948

Balali A, Valipour A, Edwards R, Moehler R (2021) Ranking effective risks on human resources threats in natural gas supply projects using ANP-COPRAS method: case study of Shiraz. Reliab Eng Syst Saf 208:107442. https://doi.org/10.1016/j.ress.2021.107442

Banaeian N, Mobli H, Fahimnia B, Nielsen IE, Omid M (2018) Green supplier selection using fuzzy group decision making methods: a case study from the agri-food industry. Comput Oper Res 89:337347. https://doi.org/10.1016/j.cor.2016.02.015

Beck MP, Lin BW (1983) Some heuristics for the consensus ranking problem. Comput Oper Res 10(1):1-7

Behzad M, Hashemkhani Zolfani S, Pamucar D, Behzad M (2020) A comparative assessment of solid waste management performance in the Nordic countries based on BWM-EDAS. J Clean Prod 266: 122008. https://doi.org/10.1016/j.jclepro.2020.122008

Bonyani A, Alimohammadlou M (2019) A novel approach to solve the problems with network structure. Oper Res. https://doi.org/10.1007/ s12351-019-00486-0

Bouzon M, Govindan K, Rodriguez CMT, Campos LMS (2016) Identification and analysis of reverse logistics barriers using fuzzy Delphi method and AHP. Resour Conserv Recycl 108:182-197. https://doi.org/10.1016/j.resconrec.2015.05.021

Brauers WKM, Zavadskas EK (2006) The MOORA method and its application to privatization in a transition economy. Control Cybern 35(2):445-469

Brauers W, Zavadskas EK (2011) MULTIMOORA optimization used to decide on a bank loan to buy property. Technol Econ Dev Econ 17(1):174-188. https://doi.org/10.3846/13928619.2011.560632

Büyüközkan G, Çifçi G (2012) A combined fuzzy AHP and fuzzy TOPSIS based strategic analysis of electronic service quality in healthcare industry. Expert Syst Appl 39(3):2341-2354. https:// doi.org/10.1016/j.eswa.2011.08.061

Cao Q, Wu J, Liang C (2015) An intuitionsitic fuzzy judgement matrix and TOPSIS integrated multi-criteria decision making method for green supplier selection. J Intell Fuzzy Syst 28(1):117-126

Ceballos B, Lamata MT, Pelta DA (2016) A comparative analysis of multi-criteria decision-making methods. Prog Artif Intell 5(4):315322. https://doi.org/10.1007/s13748-016-0093-1

Chen C-T (2000) Extensions of the TOPSIS for group decision-making under fuzzy environment. Fuzzy Sets Syst 114(1):1-9

Chen Z-S, Zhang X, Govindan K, Wang X-J, Chin K-S (2021) Thirdparty reverse logistics provider selection: a computational semantic analysis-based multi-perspective multi-attribute decision-making approach. Expert Syst Appl 166:114051. https://doi.org/10.1016/j. eswa. 2020.114051

Çifçi G, Büyüközkan G (2011) A fuzzy MCDM approach to evaluate green suppliers. Int J Comput Intellig Syst 4(5):894-909

Daniels T (2017) Environmental Planning Handbook. Routledge

Datta S, Samantra C, Mahapatra SS, Banerjee S, Bandyopadhyay A (2012) Green supplier evaluation and selection using VIKOR method embedded in fuzzy expert system with interval-valued fuzzy numbers. Int J Procure Manag 5(5):647-678
Demir L, Akpınar ME, Araz C, Ilgın MA (2018) A green supplier evaluation system based on a new multi-criteria sorting method: VIKORSORT. Expert Syst Appl 114:479-487. https://doi.org/10. 1016/j.eswa.2018.07.071

Dhiman HS, Deb D (2020) Fuzzy TOPSIS and fuzzy COPRAS based multi-criteria decision making for hybrid wind farms. Energy 202: 117755. https://doi.org/10.1016/j.energy.2020.117755

Ding X, Zhong J (2018) Power battery recycling mode selection using an extended MULTIMOORA method. Sci Program:2018

Dobos I, Vörösmarty G (2014) Green supplier selection and evaluation using DEA-type composite indicators. Int J Prod Econ 157(1):273278. https://doi.org/10.1016/j.ijpe.2014.09.026

Dorfeshan Y, Mousavi SM, Mohagheghi V, Vahdani B (2018) Selecting project-critical path by a new interval type-2 fuzzy decision methodology based on MULTIMOORA, MOOSRA and TPOP methods. Comput Ind Eng 120:160-178

Dou Y, Zhu Q, Sarkis J (2014) Evaluating green supplier development programs with a grey-analytical network process-based methodology. Eur J Oper Res 233(2):420-431. https://doi.org/10.1016/j.ejor. 2013.03.004

Durmić, E., Stević, Ž., Chatterjee, P., Vasiljević, M., \& Tomašević, M. (2020). Sustainable supplier selection using combined FUCOM Rough SAW model. Rep Mechan Eng, 1(1), 34-43. https://doi.org/ 10.31181/rme200101034c

Dwivedi R, Prasad K, Mandal N, Singh S, Vardhan M, Pamucar D (2021) Performance evaluation of an insurance company using an integrated Balanced Scorecard (BSC) and Best-Worst Method (BWM). Decis Mak: Appl Manag Eng 4(1):33-50. https://doi.org/10. 31181/dmame2104033d

Emond EJ, Mason DW (2002) A new rank correlation coefficient with application to the consensus ranking problem. Journal of MultiCriteria Decision Analysis 11(1):17-28

Fallahpour A, Olugu EU, Musa SN, Khezrimotlagh D, Wong KY (2016) An integrated model for green supplier selection under fuzzy environment: application of data envelopment analysis and genetic programming approach. Neural Comput \& Applic 27(3):707-725

Fang Y, Zhan M, Wang Y (2001) The status of recycling of waste rubber. Mater Des 22(2):123-128. https://doi.org/10.1016/S0261-3069(00) 00052-2

Fattahi R, Khalilzadeh M (2018) Risk evaluation using a novel hybrid method based on FMEA, extended MULTIMOORA, and AHP methods under fuzzy environment. Saf Sci 102:290-300

Fu X, Zhu Q, Sarkis J (2012) Evaluating green supplier development programs at a telecommunications systems provider. Int J Prod Econ 140(1):357-367. https://doi.org/10.1016/j.ijpe.2011.08.030

Fukumori K, Matsushita M, Okamoto H, Sato N, Suzuki Y, Takeuchi K (2002) Recycling technology of tire rubber. JSAE Rev 23(2):259 264. https://doi.org/10.1016/S0389-4304(02)00173-X

Ghadimi P, Wang C, Lim MK, Heavey C (2019) Intelligent sustainable supplier selection using multi-agent technology: theory and application for Industry 4.0 supply chains. Comput Ind Eng 127:588-600

Gitinavard H, Ghaderi H, Pishvaee MS (2018) Green supplier evaluation in manufacturing systems: a novel interval-valued hesitant fuzzy group outranking approach. Soft Comput 22(19):6441-6460. https://doi.org/10.1007/s00500-017-2697-1

Govindan K, Paam P, Abtahi AR (2016) A fuzzy multi-objective optimization model for sustainable reverse logistics network design. Ecol Indic 67:753-768. https://doi.org/10.1016/j.ecolind.2016.03.017

Govindan K, Rajendran S, Sarkis J, Murugesan P (2015a) Multi criteria decision making approaches for green supplier evaluation and selection: a literature review. J Clean Prod 98:66-83

Govindan K, Rajendran S, Sarkis J, Murugesan P (2015b) Multi criteria decision making approaches for green supplier evaluation and selection: a literature review. J Clean Prod 98:66-83. https://doi.org/ 10.1016/j.jclepro.2013.06.046 
Govindan K, Sivakumar R (2016) Green supplier selection and order allocation in a low-carbon paper industry: integrated multi-criteria heterogeneous decision-making and multi-objective linear programming approaches. Ann Oper Res 238(1-2):243-276

Guo S, Zhao H (2017) Fuzzy best-worst multi-criteria decision-making method and its applications. Knowl-Based Syst 121:23-31. https:// doi.org/10.1016/j.knosys.2017.01.010

Gupta V, Kapur PK, Kumar D (2017) Measuring and evaluating data distribution strategies using an integrated approach of fuzzy based MOORA and AHP. Life Cycle Reliab Safety Eng 6(1):37-45

Hafezalkotob A, Hafezalkotob A, Liao H, Herrera F (2019) An overview of MULTIMOORA for multi-criteria decision-making: theory, developments, applications, and challenges. Inform Fusion 51(December 2018):145-177. https://doi.org/10.1016/j.inffus. 2018.12.002

Hafezalkotob A, Hami-Dindar A, Rabie N, Hafezalkotob A (2018) A decision support system for agricultural machines and equipment selection: a case study on olive harvester machines. Comput Electron Agric 148:207-216

Haji A, Asiaei A, Zailani S (2015) Resources, conservation and recycling Green decision-making model in reverse logistics using FUZZYVIKOR method. Resour Conserv Recycl 103:125-138. https://doi. org/10.1016/j.resconrec.2015.05.023

Hammes G, De Souza ED, Taboada Rodriguez CM, Rojas Millan RH, Mojica Herazo JC (2020) Evaluation of the reverse logistics performance in civil construction. J Clean Prod 248:119212. https://doi. org/10.1016/j.jclepro.2019.119212

Hansen ZNL, Larsen SB, Nielsen AP, Groth A, Gregersen NG, Ghosh A (2018) Combining or separating forward and reverse logistics. Int J Logist Manag 29(1):216-236. https://doi.org/10.1108/IJLM-122016-0299

Hashemi SH, Karimi A, Tavana M (2015) An integrated green supplier selection approach with analytic network process and improved Grey relational analysis. Int J Prod Econ 159:178-191

Hezer S, Gelmez E, Özceylan E (2021) Comparative analysis of TOPSIS, VIKOR and COPRAS methods for the COVID-19 regional safety assessment. J Infect Public Health. https://doi.org/10.1016/j.jiph. 2021.03.003

Humphreys PK, Wong YK, Chan FTS (2003) Integrating environmental criteria into the supplier selection process. J Mater Process Technol 138(1):349-356

Humphreys P, McCloskey A, McIvor R, Maguire L, Glackin C (2006) Employing dynamic fuzzy membership functions to assess environmental performance in the supplier selection process. Int J Prod Res 44(12):2379-2419

Hwang C-L, Yoon K (1981) Multiple attribute decision making, vol 186. Springer, Berlin Heidelberg. https://doi.org/10.1007/978-3-64248318-9

Jabbour ABLS, Jabbour CJC (2009) Are supplier selection criteria going green? Case studies of companies in Brazil. Ind Manag Data Syst 109(4):477-495

Jarrah R, Chen C-R, Kassem M (2021) Ranking structural analysis software applications using AHP and Shannon's entropy. J Asian Arch Build Eng:1-8. https://doi.org/10.1080/13467581.2021.1900858

Jasim NA (2021) Evaluation of contractors performance in Iraqi Construction Projects Using Multiple Criteria Complex Proportional Assessment Method (COPRAS). IOP Conf Ser Mater Sci Eng 1076(1):12106

Jayaraman V, Ross AD, Agarwal A (2008) Role of information technology and collaboration in reverse logistics supply chains. Int J Log Res Appl 11(6):409-425. https://doi.org/10.1080/ 13675560701694499

Jiang P, Hu YC, Yen GF, Tsao SJ (2018) Green supplier selection for sustainable development of the automotive industry using grey decision-making. Sustain Dev 26(6):890-903
Kannan D, Govindan K, Rajendran S (2015) Fuzzy axiomatic design approach based green supplier selection: a case study from Singapore. J Clean Prod 96:194-208

Karande P, Chakraborty S (2012) A Fuzzy-MOORA approach for ERP system selection. Decis Sci Lett 1(1):11-21. https://doi.org/10.5267/ j.ds1.2012.07.001

Kengpol A, Tuominen M (2006) A framework for group decision support systems: an application in the evaluation of information technology for logistics firms. Int J Prod Econ 101(1):159-171

Khor KS, Udin ZM (2013) Reverse logistics in Malaysia: investigating the effect of green product design and resource commitment. Resour Conserv Recycl 81:71-80. https://doi.org/10.1016/j.resconrec.2013. 08.005

Kumar A, Aswin A, Gupta H (2020) Evaluating green performance of the airports using hybrid BWM and VIKOR methodology. Tour Manag 76:103941. https://doi.org/10.1016/j.tourman.2019.06.016

Kumari R, Mishra AR (2020) Multi-criteria COPRAS method based on parametric measures for intuitionistic fuzzy sets: application of green supplier selection. Iran J Sci Technol, Transac Electr Eng 44(4):1645-1662. https://doi.org/10.1007/s40998-020-00312-w

Kushwaha DK, Panchal D, Sachdeva A (2020) Risk analysis of cutting system under intuitionistic fuzzy environment. Rep Mechan Eng 1(1):162-173

Lambert S, Riopel D, Abdul-Kader W (2011) A reverse logistics decisions conceptual framework. Comput Ind Eng 61(3):561-581. https://doi.org/10.1016/j.cie.2011.04.012

Lee AHI, Kang H-Y, Hsu C-F, Hung H-C (2009) A green supplier selection model for high-tech industry. Expert Syst Appl 36(4):79177927

Lei F, Wei G, Gao H, Wu J, Wei C (2020) TOPSIS method for developing supplier selection with probabilistic linguistic information. Int $\mathrm{J}$ Fuzzy Syst 22(3):749-759. https://doi.org/10.1007/s40815-01900797-6

Li J, Yao Y, Zuo J, Li J (2020) Key policies to the development of construction and demolition waste recycling industry in China. Waste Manag 108:137-143. https://doi.org/10.1016/j.wasman. 2020.04.016

Liao C-N, Fu Y-K, Wu L-C (2016) Integrated FAHP, ARAS-F and MSGP methods for green supplier evaluation and selection. Technol Econ Dev Econ 22(5):651-669

Liao TY (2018) Reverse logistics network design for product recovery and remanufacturing. Appl Math Model 60:145-163. https://doi. org/10.1016/j.apm.2018.03.003

Lin M, Huang C, Xu Z (2020a) MULTIMOORA based MCDM model for site selection of car sharing station under picture fuzzy environment. Sustain Cities Soc 53:101873. https://doi.org/10.1016/j.scs. 2019.101873

Lin S-S, Shen S-L, Zhou A, Xu Y-S (2020b) Approach based on TOPSIS and Monte Carlo simulation methods to evaluate lake eutrophication levels. Water Res 187:116437. https://doi.org/10.1016/j.watres. 2020.116437

Liu A, Xiao Y, Ji X, Wang K, Tsai S-B, Lu H, Cheng J, Lai X, Wang J (2018a) A novel two-stage integrated model for supplier selection of Green fresh product. Sustainability 10(7):2371

Liu H-C, Yang M, Zhou M, Tian G (2018b) An integrated multi-criteria decision making approach to location planning of electric vehicle charging stations. IEEE Trans Intell Transp Syst 20(1):362-373

Liu J, Nie J, Yuan H (2020) Interactive decisions of the waste producer and the recycler in construction waste recycling. J Clean Prod 256: 120403. https://doi.org/10.1016/j.jclepro.2020.120403

Lotfi FH, Fallahnejad R (2010) Imprecise Shannon's entropy and multi attribute decision making. Entropy 12(1):53-62

Mangla SK, Govindan K, Luthra S (2016) Critical success factors for reverse logistics in Indian industries: a structural model. J Clean Prod 129:608-621. https://doi.org/10.1016/j.jclepro.2016.03.124 
Mavi RK, Goh M, Zarbakhshnia N (2017) Sustainable third-party reverse logistic provider selection with fuzzy SWARA and fuzzy MOORA in plastic industry. Int J Adv Manuf Technol 91(5-8):2401-2418. https://doi.org/10.1007/s00170-016-9880-x

Miller DW, Starr M (1969) Decisions and operations and research, 2nd edn. Prentice-Hall Inc., Englewood Cliffs

Moslem S, Farooq D, Ghorbanzadeh O, Blaschke T (2020) Application of the AHP-BWM model for evaluating driver behavior factors related to road safety: a case study for Budapest. Symmetry 12(2):243. https://doi.org/10.3390/sym12020243

Muravev D, Mijic N (2020) A novel integrated provider selection multicriteria model: the BWM-MABAC model. Decis Mak: Appl Manag Eng 3(1):60-78. https://doi.org/10.31181/dmame2003078m

Naidu MSR, Kumar PR, Chiranjeevi K (2018) Shannon and fuzzy entropy based evolutionary image thresholding for image segmentation. Alexandria Eng J 57(3):1643-1655

Noci G (1997) Designing 'green'vendor rating systems for the assessment of a supplier's environmental performance. Euro J Purchas Supply Manag 3(2):103-114

Pourhamidi M (2013) Prioritisation of knowledge management strategies in the learning organisation: an integrated Shannon's entropyTOPSIS methodology. Int J Learn Intellect Cap 10(3/4):213. https://doi.org/10.1504/IJLIC.2013.057431

Prakash C, Barua MK (2015) Integration of AHP-TOPSIS method for prioritizing the solutions of reverse logistics adoption to overcome its barriers under fuzzy environment. J Manuf Syst 37:599-615. https://doi.org/10.1016/j.jmsy.2015.03.001

Price W, Smith ED (2015) Waste tire recycling: environmental benefits and commercial challenges. Int J Environ Technol Manag 6(3/4): 362. https://doi.org/10.1504/ijetm.2006.009001

Qin J, Liu X, Pedrycz W (2017) An extended TODIM multi-criteria group decision making method for green supplier selection in interval type-2 fuzzy environment. Eur J Oper Res 258(2):626-638

Rachih H, Mhada FZ, Chiheb R (2019) Meta-heuristics for reverse logistics: a literature review and perspectives. Comput Ind Eng 127:4562. https://doi.org/10.1016/j.cie.2018.11.058

Ramírez AM, Morales VJG (2014) Improving organisational performance through reverse logistics. J Oper Res Soc 65(6):954-962. https://doi.org/10.1057/jors.2013.61

Ravi V (2014) Reverse logistics operations in automobile industry: a case study using SAP-LAP approach. Glob J Flex Syst Manag 15(4): 295-303. https://doi.org/10.1007/s40171-014-0073-x

Ravi V, Shankar R (2017) An ISM-based approach analyzing interactions among variables of reverse logistics in automobile industries. J Model Manag 12(1):36-52. https://doi.org/10.1108/JM2-08-20140066

Ray SN, Chattopadhyay S (2021) Analyzing surface air temperature and rainfall in univariate framework, quantifying uncertainty through Shannon entropy and prediction through artificial neural network. Earth Sci Inf 14(1):485-503. https://doi.org/10.1007/s12145-02000555-5

Ren J, Toniolo S (2021) Interval reference point technique for sustainable industrial processs election under uncertainties. Sustain Prod Consump 27:354-371. https://doi.org/10.1016/j.spc.2020.11.006

Rezaei J (2015) Best-worst multi-criteria decision-making method. Omega 53:49-57

Rezaei J (2016) Best-worst multi-criteria decision-making method: some properties and a linear model. Omega 64:126-130. https://doi.org/ 10.1016/j.omega.2015.12.001

Rezaei J, Nispeling T, Sarkis J, Tavasszy L (2016) A supplier selection life cycle approach integrating traditional and environmental criteria using the best worst method. J Clean Prod 135:577-588

Ribeiro DP, de Oliveira UR, da Silva César A, Aprigliano Fernandes V (2021) Evaluation of medicine reverse logistics practices in hospitals. Sustainability 13(6):3496. https://doi.org/10.3390/su13063496
Richnák P, Gubová K (2021) Green and reverse logistics in conditions of sustainable development in enterprises in Slovakia. Sustainability 13(2):581. https://doi.org/10.3390/su13020581

Rogers DS, Tibben-Lembke RS (1999) Going backwards: reverse logistics trends and practices, vol 2. Reverse Logistics Executive Council Pittsburgh, Pittsburgh

Roozbahani A, Ghased H, Hashemy Shahedany M (2020) Inter-basin water transfer planning with grey COPRAS and fuzzy COPRAS techniques: a case study in Iranian Central Plateau. Sci Total Environ 726:138499. https://doi.org/10.1016/j.scitotenv.2020. 138499

Sarabi EP, Darestani SA (2021) Developing a decision support system for logistics service provider selection employing fuzzy MULTIMOORA \&amp; BWM in mining equipment manufacturing. Appl Soft Comput 98:106849. https://doi.org/10.1016/j.asoc. 2020.106849

Sarkar B, Biswas A (2021) Pythagorean fuzzy AHP-TOPSIS integrated approach for transportation management through a new distance measure. Soft Comput 25(5):4073-4089. https://doi.org/10.1007/ s00500-020-05433-2

Shafique MN (2018) Developing the hybrid multi criteria decision making approach for green supplier evaluation, pp 162-175. https://doi. org/10.1007/978-981-10-8657-1_13

Shaik M, Abdul-Kader W (2011) Green supplier selection generic framework: a multi-attribute utility theory approach. Int J Sustain Eng 4(01):37-56

Shannon CE (1948) A mathematical theory of communication. Bell Syst Tech J 27(3):379-423

Soner O, Celik E, Akyuz E (2021) A fuzzy best-worst method (BWM) to assess the potential environmental impacts of the process of ship recycling. Marit Policy Manag:1-14. https://doi.org/10.1080/ 03088839.2021 .1889066

Storto CL (2016) Ecological efficiency based ranking of cities: a combined DEA cross-efficiency and Shannon's entropy method. Sustainability $8(2): 1-29$

Sun CC (2010) A performance evaluation model by integrating fuzzy AHP and fuzzy TOPSIS methods. Expert Syst Appl 37(12):77457754. https://doi.org/10.1016/j.eswa.2010.04.066

Svoboda J, Vaclavik V, Dvorsky T, Klus L, Zajac R (2018) The potential utilization of the rubber material after waste tire recycling. IOP Conf Ser Mater Sci Eng 385:012057. https://doi.org/10.1088/1757-899X/ 385/1/012057

Tabatabaei MH, Amiri M, Ghahremanloo M, Keshavarz-Ghorabaee M, Zavadskas EK, Antucheviciene J (2019) Hierarchical decisionmaking using a new mathematical model based on the best-worst method. Int J Comp Commu Control 14(6):710-725. https://doi.org/ 10.15837/ijccc.2019.6.3675

Tavana M (2002) Euclid: strategic alternative assessment matrix. J MultiCriteria Decis Anal 11(2):75-96

Tavana M (2003) CROSS: a multicriteria group-decision-making model for evaluating and prioritizing advanced-technology projects at NASA. Interfaces 33(3):40-56

Tavana M (2004) A subjective assessment of alternative mission architectures for the human exploration of Mars at NASA using multicriteria decision making. Comput Oper Res 31(7):1147-1164

Tavana M, Banerjee S (1995) Evaluating strategic alternatives: an analytical model. Comput Oper Res 22(7):731-743

Tavana M, Kennedy DT, Joglekar P (1996) A group decision support framework for consensus ranking of technical manager candidates. Omega 24(5):523-538

Tavana M, Li Z, Mobin M, Komaki M, Teymourian E (2016a) Multiobjective control chart design optimization using NSGA-III and MOPSO enhanced with DEA and TOPSIS. Expert Syst Appl 50: 17-39

Tavana M, LoPinto F, Smither JW (2007) A hybrid distance-based idealseeking consensus ranking model. Adv Dec Sci 2007 
Tavana M, Shaabani A, Mansouri Mohammadabadi S, Varzgani N (2020a) An integrated fuzzy AHP- fuzzy MULTIMOORA model for supply chain risk-benefit assessment and supplier selection. Int J Syst Sci: Oper Logist:1-24. https://doi.org/10.1080/23302674. 2020.1737754

Tavana M, Shaabani A, Valaei N (2020b) An integrated fuzzy framework for analyzing barriers to the implementation of continuous improvement in manufacturing. Int J Qual Reliab Manag 38(1):116-146. https://doi.org/10.1108/IJQRM-06-2019-0196

Tavana M, Zareinejad M, Santos-Arteaga FJ, Kaviani MA (2016b) A conceptual analytic network model for evaluating and selecting third-party reverse logistics providers. Int J Adv Manuf Technol 86(5-8):1705-1721. https://doi.org/10.1007/s00170-015-8208-6

Tian Z, Wang J, Wang J, Zhang H (2017) An improved MULTIMOORA approach for multi-criteria decision-making based on interdependent inputs of simplified neutrosophic linguistic information. Neural Comput \& Applic 28(1):585-597

Torabzadeh Khorasani S (2017) Green supplier evaluation by using the integrated Fuzzy AHP model and fuzzy copras. Proc Integr Optimiz Sustain 2(1):17-25. https://doi.org/10.1007/s41660-017-0027-9

Torkayesh AE, Pamucar D, Ecer F, Chatterjee P (2021) An integrated BWM-LBWA-CoCoSo framework for evaluation of healthcare sectors in Eastern Europe. Socio Econ Plan Sci:101052. https://doi.org/ 10.1016/j.seps.2021.101052

Wang C-N, Dang T-T, Nguyen N-A-T (2021a) Outsourcing reverse logistics for E-commerce retailers: a two-stage fuzzy optimization approach. Axioms 10(1):34. https://doi.org/10.3390/ axioms 10010034

Wang C-N, Dang T-T, Tibo H, Duong D-H (2021b) Assessing renewable energy production capabilities using DEA window and fuzzy TOPSIS model. Symmetry 13(2):334. https://doi.org/10.3390/ sym13020334

Wang H, Liu X, Wang N, Zhang K, Wang F, Zhang S, Wang R, Zheng P, Matsushita M (2020) Key factors influencing public awareness of household solid waste recycling in urban areas of China: a case study. Resour Conserv Recycl 158:104813. https://doi.org/10. 1016/j.resconrec.2020.104813

Wang J, Ma Q, Liu H-C (2021d) A meta-evaluation model on science and technology project review experts using IVIF-BWM and MULTIMOORA. Expert Syst Appl 168:114236. https://doi.org/ 10.1016/j.eswa.2020.114236

Wang KQ, Liu HC, Liu L, Huang J (2017) Green supplier evaluation and selection using cloud model theory and the QUALIFLEX method. Sustainability (Switzerland) 9(5):1-17. https://doi.org/10.3390/ su9050688

Wang R, Li X, Li C (2021c) Optimal selection of sustainable battery supplier for battery swapping station based on Triangular fuzzy entropy - MULTIMOORA method. J Energy Stor 34:102013. https://doi.org/10.1016/j.est.2020.102013

Wei G, Wu J, Guo Y, Wang J, Wei C (2021) An extended COPRAS model for multiple attribute group decision making based on singlevalued neutrosophic 2-tuple linguistic environment. Technol Econ Dev Econ 27:353-368. https://doi.org/10.3846/tede.2021.14057
Wu S, You X, Liu H, Wang L (2017) Improving quality function deployment analysis with the cloud MULTIMOORA method. Int Trans Oper Res 27:1600-1621. https://doi.org/10.1111/itor.12484

Wu X, Liao H, Xu Z, Hafezalkotob A, Herrera F (2018) Probabilistic linguistic MULTIMOORA: a multicriteria decision making method based on the probabilistic linguistic expectation function and the improved Borda rule. IEEE Trans Fuzzy Syst 26(6):3688-3702

Yang H, Ma M, Thompson JR, Flower RJ (2018a) Waste management, informal recycling, environmental pollution and public health. J Epidemiol Community Health 72(3):237-243. https://doi.org/10. 1136/jech-2016-208597

Yang W, Xu K, Lian J, Ma C, Bin L (2018b) Integrated flood vulnerability assessment approach based on TOPSIS and Shannon entropy methods. Ecol Indic 89:269-280. https://doi.org/10.1016/j.ecolind. 2018.02.015

Yazdani M, Alidoosti A, Zavadskas EK (2015) Risk analysis of critical infrastructures using fuzzy copras. Econ Res-Ekonomska Istraživanja 24(4):27-40. https://doi.org/10.1080/1331677x.2011. 11517478

Yeh WC, Chuang MC (2011) Using multi-objective genetic algorithm for partner selection in green supply chain problems. Expert Syst Appl 38(4):4244-4253. https://doi.org/10.1016/j.eswa.2010.09.091

You X-Y, Zhou W-Y, Zhao H, Liu H-C (2018) Robot evaluation and selection using the hesitant fuzzy linguistic MULTIMOORA method. J Test Eval 47(2):1405-1426

Zafar A, Zafar M, Sarwar A, Raza H, Khan MT (2019) A fuzzy AHP method for green supplier selection and evaluation, pp 1355-1366. https://doi.org/10.1007/978-3-319-93351-1_105

Zarbakhshnia N, Soleimani H, Ghaderi H (2018) Sustainable third-party reverse logistics provider evaluation and selection using fuzzy SWARA and developed fuzzy COPRAS in the presence of risk criteria. Appl Soft Comput 65:307-319. https://doi.org/10.1016/j. asoc.2018.01.023

Zarbakhshnia N, Soleimani H, Goh M, Razavi SS (2019) A novel multiobjective model for green forward and reverse logistics network design. J Clean Prod 208:1304-1316. https://doi.org/10.1016/j. jclepro.2018.10.138

Zavadskas EK, Antucheviciene J (2007) Multiple criteria evaluation of rural building's regeneration alternatives. Build Environ 42(1):436451. https://doi.org/10.1016/j.buildenv.2005.08.001

Zavadskas EK, Bausys R, Juodagalviene B, Garnyte-Sapranaviciene I (2017) Model for residential house element and material selection by neutrosophic MULTIMOORA method. Eng Appl Artif Intell 64: $315-324$

Zavadskas EK, Kaklauskas A, Sarka V (1994) The new method of multicriteria complex proportional assessment of projects. Technol Econ Dev Econ 1(3):131-139

Zhan J, Sun B, Zhang X (2020) PF-TOPSIS method based on CPFRS models: an application to unconventional emergency events. Comput Ind Eng 139:106192. https://doi.org/10.1016/j.cie.2019. 106192

Publisher's note Springer Nature remains neutral with regard to jurisdictional claims in published maps and institutional affiliations. 